\title{
Design, synthesis and biological evaluation of arylcinnamide hybrid derivatives as novel anticancer agents
}

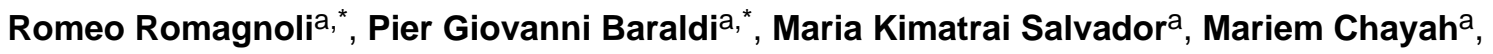 \\ M. Encarnacion Camacho ${ }^{a}$, Filippo Prencipe ${ }^{a}$, Ernest Hamel ${ }^{b}$, Francesca Consolaro ${ }^{c}$, \\ Giuseppe Basso ${ }^{c}$, and Giampietro Viola ${ }^{\mathrm{c},{ }^{*}}$ \\ aDipartimento di Scienze Chimiche e Farmaceutiche, Via Fossato di Mortara 17, Università di \\ Ferrara, 44121 Ferrara, Italy \\ bScreening Technologies Branch, Developmental Therapeutics Program, Division of Cancer \\ Treatment and Diagnosis, Frederick National Laboratory for Cancer Research, National Cancer \\ Institute, National Institutes of Health, Frederick, MD 21702, USA \\ 'Dipartimento di Salute della Donna e del Bambino, Laboratorio di Oncoematologia, Università di \\ Padova, 35131 Padova, Italy
}

\section{Abstract}

The combination of two pharmacophores into a single molecule represents one of the methods that can be adopted for the synthesis of new anticancer molecules. A series of novel antiproliferative agents designed by a pharmacophore hybridization approach, combining the arylcinnamide skeleton and an a-bromoacryloyl moiety, was synthesized and evaluated for its antiproliferative activity against a panel of seven human cancer cell lines. In addition, the new derivatives were also active on multidrug-resistant cell lines over-expressing P-glycoprotein. The biological effects of various substituents on the $N$-phenyl ring of the benzamide portion were also described. In order to study the possible mechanism of action, we observed that $4 \mathbf{p}$ slightly increased the Reactive Oxygen Species (ROS) production in HeLa cells, but, more importantly, a remarkable decrease of intracellular reduced glutathione content was detected in treated cells compared with controls. These results were confirmed by the observation that only thiol-containing antioxidants were able to significantly protect the cells from induced cell death. Altogether our results indicate that the new derivatives are endowed with good anticancer activity in vitro, and their properties may result in the development of new cancer therapeutic strategies.

\section{Keywords}

Apoptosis; Phenylcinnamides; Michael acceptor; In vitro antiproliferative activity; GSH depletion; Oxidative stress

(C) 2014 Elsevier Masson SAS. All rights reserved.

*Corresponding authors: rmr@unife.it (R. Romagnoli), pgb@unife.it (P.G. Baraldi), giampietro.viola1@ unipd.it (G. Viola). 


\section{Introduction}

Molecular hybridization, which covalently combines into a single molecule two different bioactive molecules with complementary pharmacophoric functions or with different mechanisms of action, is an effective tool to design highly active novel anticancer agents [19]. Antitumor activity of cinnamic acid derivatives was explored by many research groups [10-17]. Several laboratories reported that the phenylcinnamide scaffold showed anticancer activity against various human cancer cell lines. Phenylcinnamide derivatives with general structure 1 (Chart 1) are a class of compounds initially identified by Hergenrother et al. as potential anticancer agents $[18,19]$, with a moderate cytotoxic activity $\left(\mathrm{IC}_{50}\right.$ ranging from 1 to $10 \mu \mathrm{M})$. These compounds interact with micro-tubules by interfering with the dynamics of tubulin polymerization. By the screening of a 100-member library of amides, compound 1a was identified as one of the most active derivatives, with moderate activity against U-937 (lymphoma) and HeLa (cervical) cancer cells ( $\mathrm{IC}_{50}$ values of 3.0 and $11.3 \mu \mathrm{M}$, respectively). This derivative arrested the cell cycle at the G2/M phase and induced apoptotic cell death in the HeLa cancer cell line. Since the 3,4,5-trimethoxyphenyl substituent was demonstrated to be an essential structural requirement for optimal biological activity in numerous tubulin inhibitors, the antiproliferative activity of 1a was associated with inhibition of tubulin polymerization. Increasing the bulk of the meta-substituent on the phenyl ring of the styryl portion, from methoxy to benzyloxy, to furnish derivative $\mathbf{1 b}$, led to an increase in antiproliferative activity relative to $1 \mathrm{a}$, with $\mathrm{IC}_{50}$ values of 1.8 and $2.1 \mu \mathrm{M}$ against $\mathrm{U}-937$ and HeLa cells, respectively. Raffa et al. described a series of cinnamoyl anthranilates with general structure 2 that inhibited the proliferation of human leukemia K562 cells with $\mathrm{IC}_{50}$ values ranging from 0.57 to $5 \mu \mathrm{M}$ [20]. COMPARE analysis, effects on tubulin polymerization and on cell cycle distribution indicated that these compounds act as antitubulin agents.

The compound a-bromoacrylic acid is an alkylating agent with low chemical reactivity and devoid of cytotoxic effects $\left(\mathrm{IC}_{50}>120 \mu \mathrm{M}\right.$ on murine leukemia L1210 cells) [21]. The abromoacryloyl moiety is present in a series of potent anticancer distamycin-like minor groove binders, including PNU-166196 (brostallicin, 3), which was evaluated as a first-line single agent chemotherapy in patients with advanced or metastatic soft tissue sarcoma $[22,23]$. It has been hypothesized that the reactivity of the a-bromoacryoyl moiety results from a first-step Michael-type nucleophilic attack, followed by a further reaction of the former vinylic bromo substituent alpha to the carbonyl, leading successively either to a second nucleophilic substitution or to a beta elimination [24].

Phenylcinnamides are characterized by the presence of an $\alpha, \beta$-unsaturated carbonyl moiety, which can be considered as an Michael acceptor, an active pharmacophore often employed in the design of anticancer drugs [10,25]. Because of their ability to interact with cellular nucleophiles, Michael acceptors are often employed as a powerful tool in the design of anticancer agents $[26,27]$. Combining two bioactive pharmacophores, corresponding to the phenylcinnamide skeleton and an a-bromoacryoyl moiety, within a unique structure might result in compounds that exhibit synergistic anti-cancer effects. In a continuing study of hybrid compounds containing the a-bromoacryloyl moiety as potential anticancer drugs, we 
synthesized a novel series of hybrid compounds with general structure 4 , in which this moiety was linked to the arylcinnamide scaffold.

In particular, we synthesized two different series of compounds, characterized by the abromoacryloyl moiety located at the meta- or para-position on the phenyl of the benzylidene fragment, corresponding to compounds $\mathbf{4 a -}-\mathbf{p}$ and $\mathbf{4 q}-\mathbf{r}$, respectively. The structure-activity relationship (SAR) was investigated by the insertion of different substituents [both electronreleasing $\left(\mathrm{CH}_{3}\right.$, alkoxy, $\mathrm{OCF}_{3}, \mathrm{SCF}_{3}$, morpholin-4-yl) and electron-withdrawing $(\mathrm{F}$ and $\mathrm{Cl})$ groups] at different positions on the phenyl ring of the benzamide portion.

\section{Chemistry}

The synthetic route for the synthesis of compounds $\mathbf{4 a}-\mathbf{r}$ is outlined in Scheme 1. The two isomeric nitrocinnamic acids $\mathbf{5 a}$ and $\mathbf{5 b}$ [28] were converted to acyl chlorides in $\mathrm{CH}_{2} \mathrm{Cl}_{2}$ by $\mathrm{POCl}_{3}$ and then reacted in situ with the appropriate commercially available aniline (or 4methylbenzylamine for the preparation of $\mathbf{4 h}$ ) to furnish the corresponding nitro arylcinnamides $\mathbf{6} \mathbf{a}-\mathbf{p}$ and $\mathbf{6 q}-\mathbf{r}$, respectively. The subsequent reduction of $\mathbf{6} \mathbf{a}-\mathbf{p}$ and $\mathbf{6 q}-\mathbf{r}$ using tin(II) chloride in refluxing ethanol yielded the related amino derivatives $\mathbf{7 a - p}$ and $\mathbf{7 q}-\mathbf{r}$, respectively, which were converted to the hybrid compounds $\mathbf{4 a}-\mathbf{p}$ and $\mathbf{4 q}-\mathbf{r}$ by condensation with a-bro-moacrylic acid using 1-ethyl-3-[3-(dimethylamino)propyl]carbodiimide hydrochloride (EDCl) in dimethylformamide.

\section{Biological results and discussion}

\subsection{In vitro antiproliferative activities}

In Table 1, we report the antiproliferative effects of a-bromoacryloylamido arylcinnamides 4a-r against the growth of human cervix carcinoma (HeLa), colorectal carcinoma (HT-29 and LoVo), lymphoblastic leukemia (CEM, Jurkat and SEM) and breast carcinoma (MCF-7) cells, using the phenylcinnamides $\mathbf{1 a}$ and $\mathbf{1 b}$ as positive controls. Compound $\mathbf{1 b}$, with $\mathrm{IC}_{50}$ 's ranging from 2.2 to $21.7 \mu \mathrm{M}$, was 1.5 - to 12 -fold more potent than its methoxy counterpart 1a. With only two exceptions ( $\mathbf{4 k}$ and $\mathbf{4 l}$ ), all the molecules that were generated by the hybridization of the a-bromoacryloyl moiety with the arylcinnamide system were more active than 1a. For the benzyloxy derivative 1b, its activity was lower than that of derivatives 4b, 4e-j, 4m-r against the LoVo, CEM, Jurkat and SEM cells. Among the hybrid compounds, six of them (4e, 4i, $\mathbf{4 m -}-\mathbf{o}$ and $\mathbf{4 q})$ exhibited potent activity, with doubledigit nanomolar $\mathrm{IC}_{50}$ values against both the CEM and SEM cell lines. The validity of the hybridization approach was confirmed comparing the potency of compound 40 with that of the amino phenylcinnamide derivative 7o. This latter compound was 30-700 fold less active than the corresponding a-bromoacryloylamido derivative 4o, demonstrating that the presence of a a-bromoacryloyl moiety significantly enhanced antiproliferative activity.

With the exception of the CEM cells, compound $\mathbf{4 b}$ bearing the more lipophilic 1-naphthyl moiety exerted a more pronounced antiproliferative activity toward cell lines tested in comparison with the unsubstituted phenyl derivative $\mathbf{4 a}$. 
The antiproliferative activities of the hybrid molecules were influenced by the substituents on the phenyl ring of the aniline/benzylamino moiety. A comparison of the para-position substitution on the phenyl ring demonstrated that ERGs such as methyl (4g and $\mathbf{4 h})$, methoxy (4i) or ethoxy (4j) and morpholin-4-yl (4p) increased antiproliferative activity compared with the unsubstituted benzene derivative $\mathbf{4 a}$, whereas trifluoromethoxy $\left(\mathrm{OCF}_{3}\right.$, 4k) or trifluoromethylsulfanyl $\left(\mathrm{SCF}_{3}, \mathbf{4 l}\right)$ substituents produced a dramatic loss of potency.

Introduction of a weak electron-withdrawing group, a para-fluorine atom $(\mathbf{4 c})$, decreased the activity relative to $\mathbf{4 a}$ on six cancer cell lines, the exception being the MCF-7 cells. Moving the fluorine from the para- $(\mathbf{4 c})$ to the meta-position $(\mathbf{4 d})$ enhanced antiproliferative activity 4-15 fold in six of the seven cell lines, the exception being the CEM cells. Antiproliferative activity increased 2-30 fold by increasing halogen size from fluorine to chlorine (4f). Relative to the activity of derivative $\mathbf{4 c}$, insertion of an additional fluorine atom at the metaposition to yield $4 \mathbf{e}$ increased anti-proliferative activity (4-1300 fold) against all cancer cell lines.

By comparing the effect of substituents with opposite electronic properties at the paraposition of phenyl ring, a 2-10 fold increase in potency was observed by replacing the electron withdrawing chlorine atom (4f) with an electron-donating methyl group (4g).

The cell growth inhibitory activities of $N$-4'-tolyl and $N$-4'-methylbenzyl derivatives $\mathbf{4 g}$ and 4h, respectively, were very similar against the HeLa, LoVo and MCF-7 cells, while $\mathbf{4 h}$ had significantly reduced activity (from 2 to 7 fold) as compared with $\mathbf{4 g}$ against the remaining cell lines.

The antiproliferative activity of hybrid compounds can be further characterized in terms of the substitution pattern and the number of methoxy groups on the phenyl ring. The results show that mono-, di- or trimethoxy substitution on the $3^{\prime}, 4^{\prime}$, and/or $5^{\prime}$-positions of the phenyl ring (compounds $\mathbf{4 i}, \mathbf{4 m - \mathbf { m }}$ and $\mathbf{4 q}-\mathbf{r}$ ) were well tolerated and increased activity, usually substantially, as compared with the unsubstituted benzamide derivative $\mathbf{4 a}$.

A single methoxy substituent on the para-position of the phenyl ring (compound $\mathbf{4 i}$ ) led to a 7-15 fold increase in antiproliferative activity relative to $\mathbf{4 a}$. Comparing $\mathbf{4 i}$ with $\mathbf{4 m}$, an additional methoxy group at the meta-position had little effect on activity against HeLa, HT-29, CEM and MCF-7, but there were 2-, 3- and 20-fold increases in activity against the Jurkat, LoVo and SEM cells, respectively. The $3^{\prime}, 4^{\prime}$-dimethoxy derivative $\mathbf{4 m}$ was generally (6 out of 7 cell lines) more active than the isomeric $3^{\prime}, 5^{\prime}$-dimethoxy analogue $4 \mathbf{n}$. Finally, adding a third methoxy group to produce the $3^{\prime}, 4^{\prime}, 5^{\prime}$-trimethoxyphenyl derivative 40 caused a reduction in activity against five of the seven cancer cell lines.

Turning specifically to the para-substituted phenyl derivatives, replacing 4 '-methoxy (4i) with the $4^{\prime}$-ethoxy homologue (compound $\mathbf{4 j}$ ) produced a $2-4$ fold reduction in activity. This loss of activity became much more pronounced if the methoxy group was replaced with a bulkier trifluromethoxy (4k) or tri-fluoromethoxysulfanyl (4I) moiety.

This activity loss cannot be explained simply as being caused by a steric effect of the substitution at the para-position of the phenyl ring because insertion of an electron poor 
heterocycle such as morpholin-4-yl (compound $\mathbf{4 p}$ ) enhanced antiproliferative activity 8100 fold relative to $\mathbf{4 a}$ with six of the seven cancer cell lines (the exception was the CEM cells). Changing the location of a-bromoacryloylamido moiety from the meta-in $\mathbf{4} \mathbf{i}$ to the para-position in 4q had little effect on activity, except in the LoVo cells. Similarly, there was little difference in activity between the two isomeric trimethoxyphenyl derivatives 40 and $\mathbf{4 r}$, except in two cell lines (LoVo and SEM cells).

\subsection{Evaluation of cytotoxicity in human peripheral mononuclear cells (PBMC)}

To obtain more insights into the cytotoxic potential of these new compounds for normal human cells, two of the most active compounds ( $\mathbf{4 p}$ and $\mathbf{4 r}$ ) were assayed in vitro against human peripheral mononuclear cells (PBMC) obtained from healthy donors. As showed in Table 2, compounds $\mathbf{4 r}$ and $\mathbf{4 p}$ showed, in resting PBMC, a lesser degree of toxicity having an $\mathrm{IC}_{50}$ of about $3.5-4.0 \mu \mathrm{M}$ that is roughly $10-100$ fold lower respect to the lymphoblastic cell lines Jurkat and CEM. On the contrary they proved cytotoxic only for PHA-stimulated PBMC, suggesting that these compounds acts only in proliferating cells.

\subsection{Effects of phenylcinnamides on drug-resistant cell lines}

Drug resistance is an important therapeutic problem caused by the appearance of tumor cells endowed with differing mechanisms that confer resistance against a variety of anticancer drugs $[29,30]$. Among the most common mechanisms of resistance are those related to the over-expression of a cellular membrane protein called P-gp that mediates the efflux of various structurally unrelated drugs [29,30]. In this context, we evaluated sensitivity of two of the most active compounds $\mathbf{4 p}$ and $\mathbf{4 r}$ in two multidrug-resistant cell lines, one derived from a colon carcinoma $\left(\mathrm{LoV}_{0}{ }^{\mathrm{Doxo}}\right)$ [31], the other derived from a T-cell leukemia $\left(\mathrm{CEM}^{\mathrm{Vbl}-100}\right)$ [32], both expressing high levels of P-gp. As shown in Table 3, compounds $4 p$ and $4 r$ were equally potent toward parental cells and cells resistant to vinblastine or doxorubicin, suggesting that these compounds might be useful in the treatment of drug refractory tumors.

\subsection{In vitro inhibition of tubulin polymerization}

Previous studies have shown that compound 1a most likely derived its antiproliferative activity from an interaction at the colchicine site of tubulin, causing inhibition of tubulin polymerization [19]. To investigate whether the antiproliferative activities of the most active hybrid compounds (4e, $4 \mathbf{i}, \mathbf{4 m}, \mathbf{4 0}-\mathbf{p}, \mathbf{4 r})$ were related to an interaction with the microtubule system, these molecules were evaluated for their in vitro inhibition of the polymerization of purified tubulin [33]. All tested compounds did not inhibit tubulin assembly at concentrations as high as $20 \mu \mathrm{M}$, indicating that they were inactive as inhibitors of tubulin polymerization.

To further evaluate if the new derivatives interfered with the microtubule network, we examined the effects of $\mathbf{4 r}$ and $\mathbf{4 p}$ on HeLa cells by immunofluorescence microscopy. Shown in Fig. 1 (Panel A) is the normal microtubule network of untreated cells. Following $24 \mathrm{~h}$ of treatment with $\mathbf{4 p}$ or $\mathbf{4 r}$ at 2.5 or $5.0 \mu \mathrm{M}$ (Fig. 1, panels B-D), the microtubule network was not substantially modified in comparison with the untreated cells. Altogether these results were consistent with the conclusion that the anti-proliferative activity of these 
hybrid compounds was not derived from a direct interaction with tubulin and that it is unlikely that they act as microtubule binding agents.

\subsection{Analysis of cell cycle effects}

The effects of a $24 \mathrm{~h}$ treatment with different concentrations of $\mathbf{4 r}$ and $\mathbf{4 p}$ on cell cycle progression in HeLa cells were determined by flow cytometry (Fig. 2, Panels A and B). The compounds caused a significant $\mathrm{G} 2 / \mathrm{M}$ arrest in a concentration-dependent manner in the cell line tested, with a rise in $\mathrm{G} 2 / \mathrm{M}$ cells occurring at a concentration as low as $2 \mu \mathrm{M}$. Importantly, the increase in G2/M phase cells was accompanied by a remarkable reduction in $\mathrm{S}$ phase cells for both compounds.

\subsection{Phenylcinnamides induce apoptosis in Hela cells}

To characterize the mode of cell death induced by $\mathbf{4 r}$ and $\mathbf{4 p}$, a biparametric cytofluorimetric analysis was performed using PI, which stains DNA and enters only dead cells, and fluorescent immunolabeling of the protein annexin- $\mathrm{V}$, which binds to phosphatidylserine in a highly selective manner [34]. Dual staining for annexin- $V$ and with PI permits discrimination between live cells (annexin- $\mathrm{V}^{-} / \mathrm{PI}^{-}$), early apoptotic cells (annexin- $\mathrm{V}^{+} / \mathrm{PI}^{-}$), late apoptotic cells (annexin- $\mathrm{V}^{+} / \mathrm{PI}^{+}$) and necrotic cells (annexin $-\mathrm{V}^{-} / \mathrm{PI}^{+}$). As shown in Fig. 3 (Panels A and B), Hela cells treated with the two compounds for $24 \mathrm{~h}$ showed an accumulation of annexin- $\mathrm{V}$ positive cells that further increased after $48 \mathrm{~h}$ in comparison with the untreated cells.

\subsection{Phenylcinnamides induce caspase-dependent cell death}

To evaluate if the apoptotic cell death induced by $\mathbf{4 p}$ and $\mathbf{4 r}$ is caspase-dependent, Hela cells were treated with the two compounds in the absence or presence of the pan-caspase inhibitor z-VAD.fmk. As shown in Fig. 4 (panel A), the inhibition of caspases significantly increased cell viability suggesting a caspase-dependent process of cell death.

To determine which caspases were involved in phenylcinnamide-induced cell death, the expression of caspases was evaluated by immunoblot analysis. We observed an activation, in a time- and concentration-dependent manner, of the effector caspase- 3 and cleavage of its substrate PARP (Fig. 4, panel B). Interestingly, the two compounds did not induce activation of caspase-9, the major initiator caspase of the mitochondrial apoptotic pathway (Fig. 4, panel B). Indeed a clear activation of caspase-8 was observed for both compounds, suggesting that the induced apoptosis followed the extrinsic pathway.

\subsection{Phenylcinnamides induce downregulation of $\mathrm{Bcl}-2$ family proteins and DNA damage}

To further study the mechanism of apoptosis induction by phenylcinnamides, we evaluated the expression of proteins of the Bcl-2 family. As shown in Fig. 5, the anti-apoptotic protein Bcl-2 was decreased by treatment with $\mathbf{4 r}$ in a time dependent manner. Also $4 \mathbf{p}$ produced similar effects, but they were more evident after $48 \mathrm{~h}$ of treatment. The expression of another anti-apoptotic protein, Mcl-1, was decreased by both compounds at $2.5 \mu \mathrm{M}$, especially at $48 \mathrm{~h}$. In contrast, two pro-apoptotic proteins of the Bcl-2 family, Bak and Bax, remained practically unchanged after treatment. Of particular interest was the nearly complete disappearance of Bid expression after treatment with either compounds an effect 
that is clearly evident after only a $24 \mathrm{~h}$ treatment at the lowest concentration used. Bid is a pro-apoptotic member of the Bcl-2 family, and many studies have demonstrated that, following apoptotic stimuli, activation of caspase- 8 induces cleavage of Bid [35,36].

We also investigated whether $4 \mathbf{r}$ and $\mathbf{4 p}$ induced DNA damage by examining the expression of phosphorylated histone H2AX at Ser139 $(\gamma \mathrm{H} 2 \mathrm{~A} . \mathrm{X}) . \gamma \mathrm{H} 2 \mathrm{~A} . \mathrm{X}$ phosphorylation occurs shortly after DNA double strand break (DSB) induction, thus identifying $\gamma \mathrm{H} 2 \mathrm{~A} . \mathrm{X}$ as an early sensitive indicator of DSBs, whether induced by ionizing radiation, oxidative stress or chemical agents [37]. As shown in Fig. 5 (panel B), after a $24 \mathrm{~h}$ treatment $4 \mathrm{r}$ induced $\gamma \mathrm{H} 2 \mathrm{~A}$.X expression, while $\mathbf{4 p}$ induced this effect only after $48 \mathrm{~h}$. These findings show that both compounds induce DNA damage. Bid is also involved in promoting apoptosis following DNA damage and contributes to induction of a cell cycle arrest [38]. Thus, our findings that phenylcinnamides induce DNA damage along with strong activation of Bid could explain the arrest of the cell cycle observed after treatment of cells with these compounds.

\subsection{Phenylcinnamides induce ROS production}

To better understand the mechanism of action of $\mathbf{4 r}$, we analyzed ROS production. HeLa cells were treated for different times and with different concentrations of $\mathbf{4 r}$, and the levels of intracellular ROS were monitored using two fluorescent probes, $2^{\prime}, 7^{\prime}$ dichlorodihydrofluorescein diacetate $\left(\mathrm{H}_{2}\right.$ DCFDA) and hydroethidine (HE) [39]. As shown in Fig. 6 (panel A), flow cytometric analysis showed an early but modest increase (1-6h) in the $\mathrm{H}_{2}$ DCFDA-positive cells, and this occurred in a concentration-dependent manner. Using HE, which mainly detects superoxide anion [40], we did not detect any increase in fluorescence emission (data not shown), suggesting that superoxide anion does not play a major role. In addition, a time-course study was performed, in which the mitochondrial potential was monitored by flow cytometry with the fluorescent probe 5,5',6,6'tetrachlo-1,1',3,3'-tetrae-thylbenzimidazol-carbocyanine (JC-1) (Fig. 6, panel B). We found significant mitochondrial depolarization beginning after a $12 \mathrm{~h}$ treatment with $4 \mathrm{r}$. Since the mitochondrial membrane depolarization has been associated with mitochondrial production of ROS [41,42], these findings suggest that ROS, detected by $\mathrm{H}_{2}$ DCFDA prior to the onset of apoptosis, were not produced as a consequence of mitochondrial damage.

More importantly, to prove that ROS are involved in the mechanism of cell death of compounds $\mathbf{4 p}$ and $\mathbf{4 r}$ we analyzed cell viability in the presence of different antioxidants, including tocopherol acetate (TOC), 2,6-di-tert-butylhydroxyanisole (BHA), $\mathrm{N}$ acetylcysteine (NAC), reduced glutathione (GSH) and dithio-threitol (DTT). Surprisingly, as shown in Fig. 7 (panels A and B), only the thiol-containing scavengers (NAC, GSH and DTT) significantly increased cell viability. This suggests that ROS do not play a major role in the antiproliferative effects observed with $\mathbf{4 p}$ and $\mathbf{4 r}$.

\subsection{Phenylcinnamides induce GSH depletion}

Since only thiol containing scavengers protect from cellular death induced by phenylcinnamides, we determined whether these compounds caused a decrease in intracellular GSH content. Therefore, we analyzed HeLa cells for changes in their GSH 
levels using the fluorescent probe 5-chloromethylfluorescein diacetate (CMFDA) and flow cytometry. CMFDA is a membrane permeable dye used for determining intracellular levels of GSH [43]. As shown in Fig. 8 (Panels A and B), $24 \mathrm{~h}$ incubations with either $\mathbf{4 p}$ or 4r, concentration-dependent manners, substantially reduced CMFDA fluorescence, indicating GSH depletion. Moreover, the effect was significantly counteracted by addition of NAC to the culture medium GSH is the most abundant thiol in mammalian cells and is involved in many cellular processes, including antioxidant defense, drug detoxification, cell signaling, and cell proliferation [43-45]. Intracellular GSH loss is an early feature in the progression of cell death in response to different apoptotic stimuli and, because of its action as a primary intracellular antioxidant in the cells, a reduction in intracellular GSH content is generally believed to reflect generation of ROS [46]. Nevertheless, our findings suggest that phenylcinnamides induce apoptosis in HeLa cells by directly interacting with GSH or other intracellular thiols independently of ROS generation. In this context, we speculate that a possible mechanism of action of phenylcinnamides results from the reactivity of the abromoacryoyl moiety and its forming an irreversible adduct with GSH through a Michaeltype nucleophilic attack. This would readily lead to depletion of intracellular thiols [47].

\section{Conclusions}

The observation that the $\alpha, \beta$-unsaturated carbonyl system of phenylcinnamide and the $\alpha$ bromoacryloyl group are capable of undergoing Michael addition and thus can act as trapping agents of cellular nucleophiles led us to prepare and evaluate a series of abromoacryloylamido arylcinnamide derivatives with general structure 4 . These compounds incorporate the two moieties within their structures. We found that most of the new hybrid compounds displayed high antiproliferative activity towards a panel of seven cancer cell lines, with one-digit micromolar to double-digit nanomolar $\mathrm{IC}_{50}$ values. The new derivatives had antiproliferative activity that was significantly greater than that of the two parent compounds 1a and $\mathbf{1 b}$ against six of the seven cancer cell lines. The least active compounds were derivatives with fluorine (4c), trifluoromethoxy (4k) and trifluoromethylsulfanyl (4I) at the para-position of the phenyl ring. A positive effect was observed by the replacement of phenyl with 1-naphthyl (compounds $4 \mathbf{a}$ and $\mathbf{4 b}$, respectively), with $\mathbf{4 b}$ having $\mathrm{IC}_{50}$ values of $0.68-6.5 \mu \mathrm{M}$ as compared with $0.19-27.3 \mu \mathrm{M}$ for $\mathbf{4 a}$. Comparing the activity of hybrid compound $4 \mathbf{o}$ with that of the corresponding amino phenylcinnamide 7o, the latter showed weak or no antiproliferative activity $\left(\mathrm{IC}_{50}=2.81-63.1 \mu \mathrm{M}\right)$ against the panel of cancer cell lines, and the insertion of the a-bromoacryloyl moiety was an important molecular change, leading to a significant increase in potency $\left(\mathrm{IC}_{50}=0.018-2.3 \mu \mathrm{M}\right.$ for $\left.4 \mathbf{0}\right)$.

Preliminary mechanism of action studies demonstrated that the most potent hybrid compounds did not inhibit tubulin polymerization, but their activity seems to be related to depletion of intra-cellular GSH. Studies are underway to determine the precise molecular mechanism that leads to the decrease in intracellular GSH levels. Whether this occur through a direct chemical reaction or through interfering with the enzymatic synthesis of GSH remains to be determined. Understanding the precise mechanism may result in development of new cancer therapeutic strategies and possibly new drugs using phenylcinnamides as a lead chemotype. 


\section{Experimental protocols}

\subsection{Chemistry}

5.1.1. Materials and methods $-{ }^{1} \mathrm{H}$ and ${ }^{13} \mathrm{C}$ NMR spectra were recorded on a Bruker AC 200 and Varian 400 Mercury Plus spectrometer, respectively. Chemical shifts ( $\delta$ ) are given in ppm upfield from tetramethylsilane as internal standard, and the spectra were recorded in appropriate deuterated solvents, as indicated. Positive-ion electrospray ionization (ESI) mass spectra were recorded on a double-focusing Finnigan MAT 95 instrument with BE geometry. Melting points (mp) were determined on a Buchi-Tottoli apparatus and are uncorrected. All products reported showed ${ }^{1} \mathrm{H}$ and ${ }^{13} \mathrm{C}$ NMR spectra in agreement with the assigned structures. The purity of tested compounds was determined by combustion elemental analyses conducted by the Microanalytical Laboratory of the Chemistry Department of the University of Ferrara with a Yanagimoto MT-5 CHN recorder elemental analyzer. All tested compounds yielded data consistent with a purity of at least $95 \%$ as compared with the theoretical values. All reactions were carried out under an inert atmosphere of dry $\mathrm{N}_{2}$, unless otherwise indicated. Standard syringe techniques were used for transferring dry solvents. Reaction courses and product mixtures were routinely monitored by TLC on silica gel (precoated $\mathrm{F}_{254}$ Merck plates), and compounds were visualized with aqueous $\mathrm{KMnO}_{4}$. Flash chromatography was performed using 230-400 mesh silica gel and the indicated solvent system. Organic solutions were dried over anhydrous $\mathrm{Na}_{2} \mathrm{SO}_{4}$.

\subsubsection{General procedure A for the synthesis of compounds (6a-r)-To a} solution of nitrocinnamic acid $\mathbf{5 a}$ or $\mathbf{5 b}(386 \mathrm{mg}, 2.00 \mathrm{mmol})$ in dry chloroform $(10 \mathrm{~mL})$ containing triethylamine $(0.20 \mathrm{~mL}, 145 \mathrm{mg}, 1.43 \mathrm{mmol})$ and the appropriate aniline or $p$ tolylmethanamine ( $2.40 \mathrm{mmol}, 1.2$ equiv.) was added dropwise $\mathrm{POCl}_{3}(0.37 \mathrm{~mL}, 613 \mathrm{mg}$, $4.00 \mathrm{mmol}, 2$ equiv.) at $0{ }^{\circ} \mathrm{C}$ with stirring. After $10 \mathrm{~min}$, triethylamine $(0.21 \mathrm{~mL}, 145 \mathrm{mg}$, $1.43 \mathrm{~mol}$ ) was slowly added, and the reaction mixture was stirred for another $30 \mathrm{~min}$ at $0^{\circ} \mathrm{C}$. After this time, crushed ice was added to the reaction, and the product was extracted with $\mathrm{CH}_{2} \mathrm{Cl}_{2}(3 \times 15 \mathrm{~mL})$. The combined organic phases were washed successively with $5 \% \mathrm{HCl}$ $(10 \mathrm{~mL})$, saturated aqueous $\mathrm{NaHCO}_{3}(10 \mathrm{~mL})$, water $(10 \mathrm{~mL})$, and brine $(10 \mathrm{~mL})$, dried over $\mathrm{Na}_{2} \mathrm{SO}_{4}$ and concentrated under reduced pressure. The residue was purified by flash column chromatography on silica gel or by crystallization.

5.1.2.1. (E)-3-(3-nitrophenyl)-N-phenylacrylamide (6a): Following general procedure A, the residue purified by crystallization from ethyl ether yielded $\mathbf{6 a}$ as a yellow solid. Yield $52 \%, \mathrm{mp} 203-205{ }^{\circ} \mathrm{C} .{ }^{1} \mathrm{H}$ NMR $\left(200 \mathrm{MHz}, d_{6}\right.$-DMSO) $\delta: 7.08(\mathrm{~m}, 2 \mathrm{H}), 7.35(\mathrm{t}, J=7.2 \mathrm{~Hz}$, $2 \mathrm{H}), 7.75(\mathrm{~m}, 4 \mathrm{H}), 8.06(\mathrm{~d}, J=8.0 \mathrm{~Hz}, 1 \mathrm{H}), 8.23(\mathrm{dd}, J=8.0$ and $1.6 \mathrm{~Hz}, 1 \mathrm{H}), 8.47(\mathrm{~d}, J=$ $1.6 \mathrm{~Hz}, 1 \mathrm{H}), 10.3$ (s, 1H). MS (ESI): $[\mathrm{M}+1]^{+}=269.2$.

5.1.2.2. (E)-N-(naphthalen-1-yl)-3-(3-nitrophenyl)acrylamide (6b): Following general procedure $\mathrm{A}$, the residue purified by crystallization from ethyl ether yielded $\mathbf{6} \mathbf{b}$ as a yellow solid. Yield 72\%, mp 193-195 ${ }^{\circ} \mathrm{C} .{ }^{1} \mathrm{H}$ NMR $\left(200 \mathrm{MHz}, d_{6}\right.$-DMSO) $\delta: 7.06(\mathrm{~d}, J=15.6 \mathrm{~Hz}$, $1 \mathrm{H}), 7.46(\mathrm{~m}, 2 \mathrm{H}), 7.70(\mathrm{~m}, 2 \mathrm{H}), 7.84(\mathrm{~m}, 4 \mathrm{H}), 8.09(\mathrm{~d}, J=7.8 \mathrm{~Hz}, 1 \mathrm{H}), 8.23(\mathrm{dd}, J=7.8$ and $1.6 \mathrm{~Hz}, 1 \mathrm{H}), 8.43(\mathrm{~d}, J=1.6 \mathrm{~Hz}, 1 \mathrm{H}), 8.49(\mathrm{~d}, J=15.6 \mathrm{~Hz}, 1 \mathrm{H}), 10.5(\mathrm{~s}, 1 \mathrm{H})$. MS (ESI): $[\mathrm{M}+1]^{+}=319.2$. 
5.1.2.3. (E)-N-(4-fluorophenyl)-3-(3-nitrophenyl)acrylamide (6c): Following general procedure $\mathrm{A}$, the residue purified by crystallization from $\mathrm{CH}_{2} \mathrm{Cl}_{2}$ yielded $\mathbf{6 c}$ as a pink solid. Yield $48 \%, \mathrm{mp} 213-215^{\circ} \mathrm{C} .{ }^{1} \mathrm{H}$ NMR $\left(200 \mathrm{MHz}, d_{6}\right.$-DMSO) $\delta: 6.96(\mathrm{~d}, J=15.8 \mathrm{~Hz}, 1 \mathrm{H})$, $7.24(\mathrm{~m}, 2 \mathrm{H}), 7.74(\mathrm{~m}, 4 \mathrm{H}), 8.06(\mathrm{~d}, J=7.8 \mathrm{~Hz}, 1 \mathrm{H}), 8.22(\mathrm{dd}, J=7.8$ and $2.0 \mathrm{~Hz}, 1 \mathrm{H}), 8.48$ $(\mathrm{d}, J=2.0 \mathrm{~Hz}, 1 \mathrm{H}), 10.4$ (s, 1H). MS (ESI): $[\mathrm{M}+1]^{+}=287.2$.

5.1.2.4. (E)-N-(3-fluorophenyl)-3-(3-nitrophenyl)acrylamide (6d): Following general procedure $\mathrm{A}$, the residue purified by crystallization from $\mathrm{CH}_{2} \mathrm{Cl}_{2}$ :acetone $10: 1(\mathrm{v} / \mathrm{v})$ yielded 6d as a white solid. Yield 56\%, mp 193-195 ${ }^{\circ} \mathrm{C} .{ }^{1} \mathrm{H}$ NMR (200 MHz, $d_{6}$-DMSO) $\delta: 6.84$ (m, 1H), $6.96(\mathrm{~d}, J=15.8 \mathrm{~Hz}, 1 \mathrm{H}), 7.41(\mathrm{~m}, 2 \mathrm{H}), 7.72(\mathrm{~m}, 3 \mathrm{H}), 8.07$ (d, $J=7.8 \mathrm{~Hz}, 1 \mathrm{H})$, $8.27(\mathrm{dd}, J=7.8$ and $1.6 \mathrm{~Hz}, 1 \mathrm{H}), 8.48(\mathrm{~d}, J=1.6 \mathrm{~Hz}, 1 \mathrm{H}), 10.5$ (s, 1H). MS (ESI): [M+1] $=287.1$.

5.1.2.5. (E)-N-(3,4-difluorophenyl)-3-(3-nitrophenyl)acrylamide (6e): Following general procedure A, the residue purified by crystallization from ethyl ether yielded $\mathbf{6 e}$ as a gray solid. Yield 53\%, mp 103-105 ${ }^{\circ} \mathrm{C} .{ }^{1} \mathrm{H}$ NMR $\left(200 \mathrm{MHz}, d_{6}\right.$-DMSO) $\delta: 6.94(\mathrm{~d}, J=15.8 \mathrm{~Hz}$, $1 \mathrm{H}), 7.39(\mathrm{~m}, 2 \mathrm{H}), 7.71(\mathrm{~d}, J=7.8 \mathrm{~Hz}, 1 \mathrm{H}), 7.79(\mathrm{~d}, J=15.8 \mathrm{~Hz}, 1 \mathrm{H}), 7.94(\mathrm{~m}, 1 \mathrm{H}), 8.07$ (d, $J=7.8 \mathrm{~Hz}, 1 \mathrm{H}), 8.23(\mathrm{dd}, J=8.2$ and $1.4 \mathrm{~Hz}, 1 \mathrm{H}), 8.47(\mathrm{~d}, J=1.4 \mathrm{~Hz}, 1 \mathrm{H}), 10.6(\mathrm{~s}, 1 \mathrm{H})$. MS (ESI): $[\mathrm{M}+1]^{+}=305.2$.

5.1.2.6. (E)-N-(4-chlorophenyl)-3-(3-nitrophenyl)acrylamide (6f): Following general procedure $\mathrm{A}$, the residue purified by crystallization from a mixture of ethyl ether:acetone 10:2 (v/v) yielded $6 \mathbf{f}$ as a white solid. Yield $61 \%, \mathrm{mp} 232-234{ }^{\circ} \mathrm{C} .{ }^{1} \mathrm{H}$ NMR $\left(200 \mathrm{MHz}, d_{6^{-}}\right.$ DMSO) $\delta: 7.01(\mathrm{~d}, J=15.6 \mathrm{~Hz}, 1 \mathrm{H}), 7.38(\mathrm{~d}, J=8.8 \mathrm{~Hz}, 2 \mathrm{H}), 7.75(\mathrm{~m}, 4 \mathrm{H}), 8.06(\mathrm{~d}, J=7.8$ $\mathrm{Hz}, 1 \mathrm{H}), 8.24$ (dd, $J=7.8$ and $1.4 \mathrm{~Hz}, 1 \mathrm{H}), 8.47$ (d, $J=1.4 \mathrm{~Hz}, 1 \mathrm{H}), 10.6$ (s, 1H). MS (ESI): $[\mathrm{M}+1]^{+}=303.1$.

5.1.2.7. (E)-3-(3-nitrophenyl)-N-p-tolylacrylamide (6g): Following general procedure A, the residue purified by crystallization from acetone yielded $\mathbf{6 g}$ as a white solid. Yield $56 \%$, mp 200-202 ${ }^{\circ} \mathrm{C} .{ }^{1} \mathrm{H}$ NMR (200 MHz, $d_{6}$-DMSO) $\delta: 2.27$ (s, 3H), $6.97(\mathrm{~d}, J=15.6 \mathrm{~Hz}, 1 \mathrm{H})$, $7.13(\mathrm{~d}, J=8.4 \mathrm{~Hz}, 2 \mathrm{H}), 7.57(\mathrm{~d}, J=8.4 \mathrm{~Hz}, 2 \mathrm{H}), 7.66(\mathrm{~d}, J=15.6 \mathrm{~Hz}, 1 \mathrm{H}), 7.74(\mathrm{~m}, 1 \mathrm{H})$, $8.05(\mathrm{~d}, J=8.2 \mathrm{~Hz}, 1 \mathrm{H}), 8.22(\mathrm{dd}, J=8.2$ and $2.2 \mathrm{~Hz}, 1 \mathrm{H}), 8.46(\mathrm{~d}, J=2.2 \mathrm{~Hz}, 1 \mathrm{H}), 10.2(\mathrm{~s}$, 1H). MS (ESI): $[\mathrm{M}+1]^{+}=283.2$.

5.1.2.8. (2E)-N-(4-methylbenzyl)-3-(3-nitrophenyl)acrylamide (6h): Following general procedure $\mathrm{A}$, the residue purified by crystallization from acetone yielded $\mathbf{6 h}$ as a white solid. Yield 56\%, mp 131-133 ${ }^{\circ} \mathrm{C} .{ }^{1} \mathrm{H}$ NMR (200 MHz, $d_{6}$-DMSO) $\delta: 2.31$ (s, 3H), 4.35 (d, $J=$ $5.8 \mathrm{~Hz}, 2 \mathrm{H}), 6.84(\mathrm{~d}, J=15.8 \mathrm{~Hz}, 1 \mathrm{H}), 7.13(\mathrm{~d}, J=8.4 \mathrm{~Hz}, 2 \mathrm{H}), 7.18(\mathrm{~d}, J=8.4 \mathrm{~Hz}, 2 \mathrm{H})$, $7.57(\mathrm{~d}, J=15.7 \mathrm{~Hz}, 1 \mathrm{H}), 7.71(\mathrm{t}, J=8.0 \mathrm{~Hz}, 1 \mathrm{H}), 8.00(\mathrm{~d}, J=8.0 \mathrm{~Hz}, 1 \mathrm{H}), 8.20(\mathrm{dd}, J=8.0$ and $2.0 \mathrm{~Hz}, 1 \mathrm{H}), 8.40(\mathrm{~d}, J=2.0 \mathrm{~Hz}, 1 \mathrm{H}), 8.62(\mathrm{t}, J=5.8 \mathrm{~Hz}, 1 \mathrm{H})$. MS (ESI): $[\mathrm{M}+1]^{+}=$ 297.2 .

5.1.2.9. (E)-N-(4-methoxyphenyl)-3-(3-nitrophenyl)acrylamide (6i): Following general procedure $\mathrm{A}$, the residue purified by crystallization from $\mathrm{CH}_{2} \mathrm{Cl}_{2}$ yielded $\mathbf{6} \mathbf{i}$ as a yellow solid. Yield 58\%, mp 195- $197{ }^{\circ} \mathrm{C} .{ }^{1} \mathrm{H}$ NMR (200 MHz, $d_{6}$-DMSO) $\delta: 3.74$ (s, 3H), 6.90 (d, 
$J=15.8 \mathrm{~Hz}, 1 \mathrm{H}), 6.94(\mathrm{~d}, J=9.0 \mathrm{~Hz}, 2 \mathrm{H}), 7.60(\mathrm{~d}, J=9.0 \mathrm{~Hz}, 2 \mathrm{H}), 7.74(\mathrm{~m}, 2 \mathrm{H}), 8.08(\mathrm{~d}, J$ $=7.8 \mathrm{~Hz}, 1 \mathrm{H}), 8.22(\mathrm{dd}, J=7.8$ and $2.0 \mathrm{~Hz}, 1 \mathrm{H}), 8.46(\mathrm{~d}, J=2.0 \mathrm{~Hz}, 1 \mathrm{H}), 10.2(\mathrm{~s}, 1 \mathrm{H})$. MS (ESI): $[\mathrm{M}+1]^{+}=299.2$.

5.1.2.10. (E)-N-(4-ethoxyphenyl)-3-(3-nitrophenyl)acrylamide (6j): Following general procedure $\mathrm{A}$, the crude residue purified by flash chromatography, using ethyl acetate:petroleum ether 1:1 (v:v) for elution, furnished $\mathbf{6 j}$ as a yellow solid. Yield $56 \%, \mathrm{mp}$ 180-182 ${ }^{\circ} \mathrm{C} .{ }^{1} \mathrm{H}$ NMR $\left(200 \mathrm{MHz}, d_{6}\right.$-DMSO) $\delta: 1.32(\mathrm{t}, J=6.8 \mathrm{~Hz}, 3 \mathrm{H}), 4.02(\mathrm{q}, J=6.8 \mathrm{~Hz}$, $2 \mathrm{H}), 6.93(\mathrm{~m}, 3 \mathrm{H}), 7.64(\mathrm{~m}, 3 \mathrm{H}), 7.74(\mathrm{~m}, 1 \mathrm{H}), 8.05(\mathrm{~d}, J=7.8 \mathrm{~Hz}, 1 \mathrm{H}), 8.21(\mathrm{dd}, J=7.8$ and $2.2 \mathrm{~Hz}, 1 \mathrm{H}), 8.46(\mathrm{~d}, J=2.2 \mathrm{~Hz}, 1 \mathrm{H}), 10.2(\mathrm{~s}, 1 \mathrm{H})$. MS (ESI): $[\mathrm{M}+1]^{+}=283.2$.

\subsubsection{1. (E)-N-(4-trifluoromethoxyphenyl)-3-(4-nitrophenyl)acryl-amide (6k):} Following general procedure A, the residue purified by crystallization from ethyl ether yielded $6 \mathbf{k}$ as a white solid. Yield $83 \%, \mathrm{mp} 208-210{ }^{\circ} \mathrm{C} .{ }^{1} \mathrm{H}$ NMR (200 MHz, $d_{6}$-DMSO) $\delta$ : 7.00 (d, $J=15.8 \mathrm{~Hz}, 1 \mathrm{H}), 7.09$ (d, $J=8.2 \mathrm{~Hz}, 2 \mathrm{H}), 7.24$ (d, $J=8.2 \mathrm{~Hz}, 2 \mathrm{H}), 7.33$ (d, $J=$ $15.6 \mathrm{~Hz}, 1 \mathrm{H}), 7.84(\mathrm{t}, J=8.8 \mathrm{~Hz}, 1 \mathrm{H}), 8.07(\mathrm{~d}, J=8.6 \mathrm{~Hz}, 1 \mathrm{H}), 8.25(\mathrm{dd}, J=8.6$ and $2.0 \mathrm{~Hz}$, $1 \mathrm{H}), 8.47(\mathrm{~s}, J=2.0 \mathrm{~Hz}, 1 \mathrm{H}), 10.6(\mathrm{~s}, 1 \mathrm{H})$. MS (ESI): $[\mathrm{M}+1]^{+}=299.1$.

\subsubsection{2. (E)-3-(3-nitrophenyl)-N-(4-(trifluoromethylthio)phenyl) acrylamide (61):} Following general procedure A, the residue purified by crystallization from ethyl ether yielded $6 \mathbf{l}$ as a white solid. Yield $68 \%, \mathrm{mp} 204-206{ }^{\circ} \mathrm{C} .{ }^{1} \mathrm{H}$ NMR $\left(200 \mathrm{MHz}, d_{6}\right.$-DMSO) $\delta$ : $6.66(\mathrm{~d}, J=8.6 \mathrm{~Hz}, 2 \mathrm{H}), 6.90(\mathrm{~d}, J=16.0 \mathrm{~Hz}, 1 \mathrm{H}), 7.34(\mathrm{~d}, J=8.6 \mathrm{~Hz}, 2 \mathrm{H}), 7.54(\mathrm{t}, J=8.0$ $\mathrm{Hz}, 1 \mathrm{H}), 7.81(\mathrm{~d}, J=16.0 \mathrm{~Hz}, 1 \mathrm{H}), 8.08(\mathrm{~d}, J=8.0 \mathrm{~Hz}, 1 \mathrm{H}), 8.24(\mathrm{dd}, J=8.0$ and $1.4 \mathrm{~Hz}$, $1 \mathrm{H}), 8.49(\mathrm{~d}, J=1.4 \mathrm{~Hz}, 1 \mathrm{H}), 10.7(\mathrm{~s}, 1 \mathrm{H})$. MS (ESI): $[\mathrm{M}+1]^{+}=369.1$.

5.1.2.13. (E)-N-(3,4-dimethoxyphenyl)-3-(3-nitrophenyl)acrylamide (6m): Following general procedure $\mathrm{A}$, the residue purified by crystallization from $\mathrm{CH}_{2} \mathrm{Cl}_{2}$ yielded $6 \mathrm{~m}$ as an orange solid. Yield $46 \%, \mathrm{mp} 159-161{ }^{\circ} \mathrm{C} .{ }^{1} \mathrm{H}$ NMR (200 MHz, $d_{6}$-DMSO) $\delta: 3.63(\mathrm{~s}, 3 \mathrm{H}$ ), $3.76(\mathrm{~s}, 3 \mathrm{H}), 6.91(\mathrm{~d}, J=8.8 \mathrm{~Hz}, 1 \mathrm{H}), 6.95(\mathrm{~d}, J=15.6 \mathrm{~Hz}, 1 \mathrm{H}), 7.24(\mathrm{dd}, J=8.6$ and $2.2 \mathrm{~Hz}$, $1 \mathrm{H}), 7.42(\mathrm{~d}, J=2.2 \mathrm{~Hz}, 1 \mathrm{H}), 7.74(\mathrm{~m}, 2 \mathrm{H}), 8.04(\mathrm{~d}, J=8.2 \mathrm{~Hz}, 1 \mathrm{H}), 8.22(\mathrm{dd}, J=8.2$ and $2.0 \mathrm{~Hz}, 1 \mathrm{H}), 8.46(\mathrm{~d}, J=2.0 \mathrm{~Hz}, 1 \mathrm{H}), 10.2(\mathrm{~s}, 1 \mathrm{H}) . \mathrm{MS}(\mathrm{ESI}):[\mathrm{M}+1]^{+}=329.2$.

\subsubsection{4. (E)-N-(3,5-dimethoxyphenyl)-3-(3-nitrophenyl)acrylamide (6n): Following} general procedure $\mathrm{A}$, the crude residue purified by flash chromatography, using ethyl acetate:petroleum ether 1:1 (v:v) for elution, furnished $\mathbf{6 n}$ as a yellow solid. Yield 54\%, mp 172-174 ${ }^{\circ} \mathrm{C} .{ }^{1} \mathrm{H}$ NMR (200 MHz, $d_{6}$-DMSO) $\delta: 3.82$ (s, 6H), 6.24 (s, 2H), 6.97 (s, 1H), 7.01 (d, $J=15.8 \mathrm{~Hz}, 1 \mathrm{H}), 7.66(\mathrm{~d}, J=15.8 \mathrm{~Hz}, 1 \mathrm{H}), 7.74(\mathrm{t}, J=8.2 \mathrm{~Hz}, 1 \mathrm{H}), 8.04(\mathrm{~d}, J=8.2 \mathrm{~Hz}$, $1 \mathrm{H}), 8.27$ (dd, $J=8.2$ and $2.0 \mathrm{~Hz}, 1 \mathrm{H}), 8.45$ (d, $J=2.0 \mathrm{~Hz}, 1 \mathrm{H}), 10.4$ (s, 1H). MS (ESI): [M $+1]^{+}=329.2$.

5.1.2.15. (E)-N-(3,4,5-trimethoxyphenyl)-3-(3-nitrophenyl)acrylamide (60): Following general procedure $\mathrm{A}$, the crude residue purified by flash chromatography, using EtOAc:petroleum ether 8:2 (v:v) for elution, furnished $\mathbf{6 0}$ as a yellow solid. Yield 54\%, mp 190-192 ${ }^{\circ} \mathrm{C} .{ }^{1} \mathrm{H}$ NMR (200 MHz, $d_{6}$-DMSO) $\delta: 3.63$ (s, 3H), 3.77 (s, 6H), 6.94 (d, $J=15.8$ $\mathrm{Hz}, 1 \mathrm{H}), 7.09$ (s, 2H), 7.64 (d, $J=15.8 \mathrm{~Hz}, 1 \mathrm{H}), 7.78(\mathrm{t}, J=7.8 \mathrm{~Hz}, 1 \mathrm{H}), 8.04(\mathrm{~d}, J=7.8 \mathrm{~Hz}$, 
1H), 8.23 (dd, $J=7.8$ and $2.0 \mathrm{~Hz}, 1 \mathrm{H}), 8.44$ (d, $J=2.0 \mathrm{~Hz}, 1 \mathrm{H}), 10.2(\mathrm{~s}, 1 \mathrm{H})$. MS (ESI): [M $+1]^{+}=359.2$.

5.1.2.16. (E)-N-(4-morpholinophenyl)-3-(3-nitrophenyl)acrylamide (6p): Following general procedure A, the crude residue purified by flash chromatography, using EtOAc for elution, furnished $\mathbf{6 p}$ as a yellow solid. Yield $62 \%, \mathrm{mp} 210-212{ }^{\circ} \mathrm{C} .{ }^{1} \mathrm{H}$ NMR $(200 \mathrm{MHz}$, $d_{6}$-DMSO) $\delta: 3.09$ (t, $\left.J=4.6 \mathrm{~Hz}, 4 \mathrm{H}\right), 3.75(\mathrm{t}, J=4.6 \mathrm{~Hz}, 4 \mathrm{H}), 6.99(\mathrm{~m}, 2 \mathrm{H}), 7.64(\mathrm{~m}, 3 \mathrm{H})$, $7.77(\mathrm{~m}, 2 \mathrm{H}), 8.04(\mathrm{~d}, J=7.8 \mathrm{~Hz}, 1 \mathrm{H}), 8.25(\mathrm{dd}, J=7.8$ and $1.4 \mathrm{~Hz}, 1 \mathrm{H}), 8.46(\mathrm{~d}, J=1.4$ $\mathrm{Hz}, 1 \mathrm{H}), 10.1$ (s, 1H). MS (ESI): $[\mathrm{M}+1]^{+}=354.2$.

5.1.2.17. (E)-N-(4-methoxyphenyl)-3-(4-nitrophenyl)acrylamide (6q): Following general procedure A, the residue purified by crystallization from petroleum ether yielded $\mathbf{6 q}$ as a yellow solid. Yield $74 \%$, mp $113-115^{\circ} \mathrm{C} .{ }^{1} \mathrm{H}$ NMR (200 MHz, $d_{6}$-DMSO) $\delta: 3.81(\mathrm{~s}, 3 \mathrm{H})$, $6.94(\mathrm{~d}, J=15.8 \mathrm{~Hz}, 1 \mathrm{H}), 7.09(\mathrm{~d}, J=9.0 \mathrm{~Hz}, 2 \mathrm{H}), 7.34(\mathrm{~d}, J=9.0 \mathrm{~Hz}, 2 \mathrm{H}), 7.64(\mathrm{~d}, J=$ $15.8 \mathrm{~Hz}, 1 \mathrm{H}), 7.90$ (d, $J=8.8 \mathrm{~Hz}, 2 \mathrm{H}), 8.27$ (d, $J=8.6 \mathrm{~Hz}, 2 \mathrm{H}), 10.6$ (s, 1H). MS (ESI): [M $+1]^{+}=299.1$.

5.1.2.18. (E)-N-(3,4,5-trimethoxyphenyl)-3-(4-nitrophenyl)acrylamide (6r): Following general procedure $\mathrm{A}$, the residue purified by crystallization from ethyl ether yielded $\mathbf{6 r}$ as a yellow solid. Yield 67\%, mp 196-198 ${ }^{\circ} \mathrm{C} .{ }^{1} \mathrm{H}$ NMR $\left(200 \mathrm{MHz}, d_{6}\right.$-DMSO) $\delta: 3.63(\mathrm{~s}, 3 \mathrm{H})$, $3.77(\mathrm{~s}, 6 \mathrm{H}), 6.94(\mathrm{~d}, J=15.8 \mathrm{~Hz}, 1 \mathrm{H}), 7.10(\mathrm{~s}, 2 \mathrm{H}), 7.63(\mathrm{~d}, J=15.8 \mathrm{~Hz}, 1 \mathrm{H}), 7.86(\mathrm{~d}, J=$ $8.8 \mathrm{~Hz}, 2 \mathrm{H}), 8.28(\mathrm{~d}, J=8.8 \mathrm{~Hz}, 2 \mathrm{H}), 10.3(\mathrm{~s}, 1 \mathrm{H}) . \mathrm{MS}(\mathrm{ESI}):[\mathrm{M}+1]^{+}=359.1$.

\subsubsection{General procedure $B$ for the synthesis of compounds (7a-r)-To a} suspension of nitroarylcinnamide derivatives $\mathbf{6 a}-\mathbf{r}(1.00 \mathrm{mmol})$ in absolute ethanol $(10 \mathrm{~mL})$ was added $\mathrm{SnCl}_{2} \cdot 2 \mathrm{H}_{2} \mathrm{O}(1.13 \mathrm{~g}, 5.00 \mathrm{mmol})$, and the stirring mixture was refluxed for $1.5 \mathrm{~h}$. After this time, the reaction was cooled to room temperature and treated with cold water (15 $\mathrm{mL}$ ), and the suspension was carefully adjusted to $\mathrm{pH} 8$ with $\mathrm{NaHCO}_{3}$. The mixture was extracted with EtOAc $(3 \times 15 \mathrm{~mL})$, the combined organic phase was washed with water $(10$ $\mathrm{mL})$ and brine $(10 \mathrm{~mL})$, dried over anhydrous $\mathrm{Na}_{2} \mathrm{SO}_{4}$ and concentrated under reduced pressure. The crude residue was subjected to column chromatography on silica gel or purified by crystallization with ethyl ether.

5.1.3.1. (E)-3-(3-aminophenyl)-N-phenylacrylamide (7a): Following general procedure B, the crude residue purified by flash chromatography, using EtOAc:petroleum ether 1:1 (v:v)

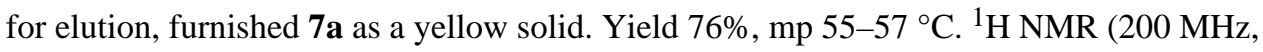
$d_{6}$-DMSO) $\delta: 5.23(\mathrm{bs}, 2 \mathrm{H}), 6.64(\mathrm{~m}, 2 \mathrm{H}), 6.74(\mathrm{~d}, J=6.6 \mathrm{~Hz}, 2 \mathrm{H}), 7.08(\mathrm{~m}, 2 \mathrm{H}), 7.33(\mathrm{~m}$, $3 \mathrm{H}), 7.71(\mathrm{~d}, J=8.6 \mathrm{~Hz}, 2 \mathrm{H}), 10.2(\mathrm{~s}, 1 \mathrm{H})$. MS (ESI): $[\mathrm{M}+1]^{+}=239.1$.

5.1.3.2. (E)-3-(3-aminophenyl)-N-(naphthalen-1-yl)acrylamide (7b): Following general procedure $\mathrm{B}$, the crude residue purified by flash chromatography, using EtOAc:petroleum ether 1:1 (v:v) for elution, furnished $7 \mathbf{b}$ as a yellow solid. Yield $72 \%, \mathrm{mp} 132-134{ }^{\circ} \mathrm{C} .{ }^{1} \mathrm{H}$ NMR (200 MHz, $d_{6}$-DMSO) $\delta: 5.48(\mathrm{bs}, 2 \mathrm{H}), 6.66(\mathrm{~d}, J=15.6 \mathrm{~Hz}, 1 \mathrm{H}), 6.89(\mathrm{~m}, 2 \mathrm{H}), 7.10$ $(\mathrm{m}, 2 \mathrm{H}), 7.49(\mathrm{~m}, 4 \mathrm{H}), 7.69(\mathrm{~d}, J=15.6 \mathrm{~Hz}, 1 \mathrm{H}), 7.82(\mathrm{~m}, 2 \mathrm{H}), 8.42(\mathrm{~d}, J=1.6 \mathrm{~Hz}, 1 \mathrm{H})$, 10.4 (s, 1H). MS (ESI): $[\mathrm{M}+1]^{+}=319.2$. 
5.1.3.3. (E)-3-(3-aminophenyl)-N-(4-fluorophenyl)acrylamide (7c): Following general procedure $\mathrm{B}$, the crude residue purified by flash chromatography, using EtOAc:petroleum ether 1:1 (v:v) for elution, furnished $7 \mathbf{c}$ as a white solid. Yield $52 \%, \mathrm{mp} 174-176{ }^{\circ} \mathrm{C} .{ }^{1} \mathrm{H}$ NMR (200 MHz, $d_{6}$-DMSO) $\delta: 5.23(\mathrm{bs}, 2 \mathrm{H}), 6.62(\mathrm{~m}, 1 \mathrm{H}), 6.73(\mathrm{~m}, 3 \mathrm{H}), 7.04(\mathrm{~d}, J=8.0$ $\mathrm{Hz}, 1 \mathrm{H}), 7.17$ (m, 2H), 7.37 (d, $J=15.6 \mathrm{~Hz}, 1 \mathrm{H}), 7.72$ (m, 2H), 10.2 (s, 1H). MS (ESI): [M $+1]^{+}=257.2$.

5.1.3.4. (E)-3-(3-aminophenyl)-N-(3-fluorophenyl)acrylamide (7d): Following general procedure $\mathrm{B}$, the crude residue purified by flash chromatography, using EtOAc:petroleum ether 1:1 (v:v) for elution, furnished $7 \mathbf{d}$ as a white solid. Yield $61 \%$, mp $90-92{ }^{\circ} \mathrm{C} .{ }^{1} \mathrm{H}$ NMR (200 MHz, $d_{6}$-DMSO) $\delta: 5.34(\mathrm{bs}, 2 \mathrm{H}), 6.26(\mathrm{~d}, J=15.6 \mathrm{~Hz}, 1 \mathrm{H}), 6.71(\mathrm{~m}, 1 \mathrm{H}), 6.81(\mathrm{~m}$, $2 \mathrm{H}), 6.89(\mathrm{~m}, 1 \mathrm{H}), 7.06(\mathrm{~m}, 1 \mathrm{H}), 7.34(\mathrm{~m}, 2 \mathrm{H}), 7.39(\mathrm{~d}, J=15.6 \mathrm{~Hz}, 1 \mathrm{H}), 7.75(\mathrm{dd}, J=10.6$ and $1.2 \mathrm{~Hz}, 1 \mathrm{H}), 10.4(\mathrm{~s}, 1 \mathrm{H})$. MS (ESI): $[\mathrm{M}+1]^{+}=257.2$.

5.1.3.5. (E)-3-(3-aminophenyl)-N-(3,4-difluorophenyl)acrylamide (7e): Following general procedure $\mathrm{B}$, the crude residue purified by flash chromatography, using EtOAc:petroleum ether 1:1 (v:v) for elution, furnished $\mathbf{7 e}$ as a yellow solid. Yield 78\%, mp 126-128 ${ }^{\circ} \mathrm{C} .{ }^{1} \mathrm{H}$ NMR (200 MHz, $d_{6}$-DMSO) $\delta: 5.23(\mathrm{bs}, 2 \mathrm{H}), 6.67(\mathrm{~m}, 3 \mathrm{H}), 6.74(\mathrm{~m}, 1 \mathrm{H})$, $7.04(\mathrm{t}, J=8.0 \mathrm{~Hz}, 1 \mathrm{H}), 7.40(\mathrm{~m}, 2 \mathrm{H}), 7.93(\mathrm{~m}, 2 \mathrm{H}), 10.4$ (s, 1H). MS (ESI): [M+1] ${ }^{+}=$ 275.2 .

5.1.3.6. (E)-3-(3-aminophenyl)-N-(4-chlorophenyl)acrylamide (7f): Following general procedure $\mathrm{B}$, the crude residue purified by crystallization from $\mathrm{Et}_{2} \mathrm{O}$ furnished $\mathbf{7 f}$ as an orange solid. Yield $70 \%, \mathrm{mp} 170-172{ }^{\circ} \mathrm{C} .{ }^{1} \mathrm{H}$ NMR $\left(200 \mathrm{MHz}, d_{6}\right.$-DMSO) $\delta: 5.88(\mathrm{bs}, 2 \mathrm{H})$, $6.73(\mathrm{~m}, 3 \mathrm{H}), 6.86(\mathrm{~m}, 1 \mathrm{H}), 7.13(\mathrm{t}, J=8.0 \mathrm{~Hz}, 1 \mathrm{H}), 7.48(\mathrm{~m}, 3 \mathrm{H}), 7.74(\mathrm{~d}, J=9.0 \mathrm{~Hz}, 2 \mathrm{H})$, 10.3 (s, 1H). MS (ESI): $[\mathrm{M}+1]^{+}=273.1$.

5.1.3.7. (E)-3-(3-aminophenyl)-N-p-tolylacrylamide (7g): Following general procedure B, the crude residue purified by flash chromatography, using EtOAc:petroleum ether 3:7 (v:v) for elution, furnished $7 \mathrm{~g}$ as a yellow solid. Yield, $74 \%, \mathrm{mp} 181-183{ }^{\circ} \mathrm{C} .{ }^{1} \mathrm{H}$ NMR (200 MHz, $d_{6}$-DMSO) $\delta: 2.26(\mathrm{~s}, 3 \mathrm{H}), 5.22(\mathrm{bs}, 2 \mathrm{H}), 6.64(\mathrm{~m}, 2 \mathrm{H}), 6.71(\mathrm{~d}, J=8.8 \mathrm{~Hz}, 2 \mathrm{H}), 7.11$ $(\mathrm{m}, 3 \mathrm{H}), 7.35(\mathrm{~d}, J=15.6 \mathrm{~Hz}, 1 \mathrm{H}), 7.56(\mathrm{~d}, J=8.8 \mathrm{~Hz}, 2 \mathrm{H}), 10.1(\mathrm{~s}, 1 \mathrm{H}) . \mathrm{MS}(\mathrm{ESI}):[\mathrm{M}+1]^{+}$ $=253.2$.

5.1.3.8. (2E)-3-(3-aminophenyl)-N-(4-methylbenzyl)acrylamide (7h): Following general procedure $\mathrm{B}$, the crude residue purified by flash chromatography, using EtOAc:petroleum ether 6:4 (v:v) for elution, furnished $4 \mathbf{h}$ as a yellow solid. Yield 55\%; mp $83-85{ }^{\circ} \mathrm{C} .{ }^{1} \mathrm{H}$ NMR (200 MHz, $d_{6}$-DMSO) $\delta: 2.30(\mathrm{~s}, 3 \mathrm{H}), 4.32(\mathrm{~d}, J=5.8 \mathrm{~Hz}, 2 \mathrm{H}), 5.18(\mathrm{bs}, 2 \mathrm{H}), 6.59$ (m, 4H), $7.03(\mathrm{~m}, 5 \mathrm{H}), 7.24$ (d, $J=15.8 \mathrm{~Hz}, 1 \mathrm{H}), 8.54$ (t, $J=5.8 \mathrm{~Hz}, 1 \mathrm{H})$. MS (ESI): $[\mathrm{M}+1]^{+}$ $=267.2$.

5.1.3.9. (E)-3-(3-aminophenyl)-N-(4-methoxyphenyl)acrylamide (7i): Following general procedure $\mathrm{B}$, the crude residue purified by flash chromatography, using EtOAc:petroleum ether 6:4 (v:v) for elution, furnished $7 \mathbf{i}$ as a yellow solid. Yield $93 \%, \mathrm{mp} 173-175{ }^{\circ} \mathrm{C} .{ }^{1} \mathrm{H}$ NMR (200 MHz, $d_{6}$-DMSO) $\delta: 3.73(\mathrm{~s}, 3 \mathrm{H}), 5.22(\mathrm{bs}, 2 \mathrm{H}), 6.62(\mathrm{~m}, 2 \mathrm{H}), 6.76(\mathrm{~m}, 2 \mathrm{H}), 6.88$ 
(d, $J=9.0 \mathrm{~Hz}, 2 \mathrm{H}), 7.07$ (t, $J=7.8 \mathrm{~Hz}, 1 \mathrm{H}), 7.34(\mathrm{~d}, J=15.6 \mathrm{~Hz}, 1 \mathrm{H}), 7.58(\mathrm{~d}, J=9.0 \mathrm{~Hz}$, 2H), 10.0 (s, 1H). MS (ESI): $[\mathrm{M}+1]^{+}=329.1$.

5.1.3.10. (E)-3-(4-aminophenyl)-N-(4-ethoxyphenyl)acrylamide (7j): Following general procedure $\mathrm{B}$, the crude residue purified by flash chromatography, using EtOAc:petroleum ether 1:1 (v:v) for elution, furnished $7 \mathbf{j}$ as a yellow solid. Yield $85 \%, \mathrm{mp} 125-127{ }^{\circ} \mathrm{C} .{ }^{1} \mathrm{H}$ NMR (200 MHz, $\left.\mathrm{CDCl}_{3}\right) \delta: 1.31(\mathrm{t}, J=6.8 \mathrm{~Hz}, 3 \mathrm{H}), 4.00(\mathrm{q}, J=6.8 \mathrm{~Hz}, 2 \mathrm{H}), 5.22(\mathrm{bs}, 2 \mathrm{H})$, $6.58(\mathrm{~m}, 1 \mathrm{H}), 6.69(\mathrm{~m}, 3 \mathrm{H}), 6.87(\mathrm{~d}, J=9.2 \mathrm{~Hz}, 2 \mathrm{H}), 7.03(\mathrm{t}, J=7.8 \mathrm{~Hz}, 1 \mathrm{H}), 7.41(\mathrm{~d}, J=$ $15.6 \mathrm{~Hz}, 1 \mathrm{H}), 7.57$ (d, $J=9.2 \mathrm{~Hz}, 2 \mathrm{H}), 10.0(\mathrm{~s}, 1 \mathrm{H})$. MS (ESI): $[\mathrm{M}+1]^{+}=269.2$.

\subsubsection{1. (E)-3-(3-aminophenyl)-N-(4-trifluoromethoxyphenyl)acrylamide (7k):}

Following general procedure $\mathrm{B}$, the crude residue purified by flash chromatography, using EtOAc for elution, furnished $\mathbf{7 k}$ as a yellow solid. Yield $83 \%, \mathrm{mp}>300{ }^{\circ} \mathrm{C} .{ }^{1} \mathrm{H}$ NMR $(200$ $\mathrm{MHz}, d_{6}$-DMSO) $\delta: 5.24(\mathrm{bs}, 2 \mathrm{H}), 6.64(\mathrm{~m}, 2 \mathrm{H}), 6.72(\mathrm{~m}, 2 \mathrm{H}), 7.20(\mathrm{t}, J=7.8 \mathrm{~Hz}, 1 \mathrm{H}), 7.32$ (d, $J=8.2 \mathrm{~Hz}, 2 \mathrm{H}), 7.39$ (d, $J=15.6 \mathrm{~Hz}, 1 \mathrm{H}), 7.82(\mathrm{~d}, J=9.0 \mathrm{~Hz}, 2 \mathrm{H}), 10.4(\mathrm{~s}, 1 \mathrm{H}) . \mathrm{MS}$ (ESI): $[\mathrm{M}+1]^{+}=323.1$.

\subsubsection{2. (E)-3-(3-aminophenyl)-N-(4-(trifluoromethylthio)phenyl) acrylamide (7I):} Following general procedure $\mathrm{B}$, the crude residue purified by flash chromatography, using EtOAc for elution, furnished $7 \mathbf{l}$ as a yellow solid. Yield 55\%, mp $173-175^{\circ} \mathrm{C} .{ }^{1} \mathrm{H}$ NMR (200 MHz, $d_{6}$-DMSO) $\delta: 5.42(\mathrm{bs}, 2 \mathrm{H}), 6.66(\mathrm{~m}, 2 \mathrm{H}), 6.78(\mathrm{~m}, 2 \mathrm{H}), 7.09(\mathrm{t}, J=8.0 \mathrm{~Hz}, 1 \mathrm{H})$, $7.42(\mathrm{~d}, J=15.6 \mathrm{~Hz}, 1 \mathrm{H}), 7.66(\mathrm{~d}, J=8.8 \mathrm{~Hz}, 2 \mathrm{H}), 7.84(\mathrm{~d}, J=8.4 \mathrm{~Hz}, 2 \mathrm{H}), 10.5(\mathrm{~s}, 1 \mathrm{H})$. MS (ESI): $[\mathrm{M}+1]^{+}=339.2$.

\subsubsection{3. (E)-3-(3-aminophenyl)-N-(3,4-dimethoxyphenyl)acrylamide (7m): Following} general procedure $\mathrm{B}$, the crude residue purified by flash chromatography, using EtOAc:petroleum ether 7:3 (v:v) for elution, furnished $\mathbf{7 m}$ as a yellow solid. Yield $>95 \%$, mp 81-83 ${ }^{\circ} \mathrm{C} .{ }^{1} \mathrm{H}$ NMR (200 MHz, $d_{6}$-DMSO) $8: 3.72(\mathrm{~s}, 3 \mathrm{H}), 3.74(\mathrm{~s}, 3 \mathrm{H}), 5.43$ (bs, 2H), $6.62(\mathrm{~m}, 2 \mathrm{H}), 6.77(\mathrm{~m}, 2 \mathrm{H}), 6.88(\mathrm{~d}, J=8.8 \mathrm{~Hz}, 1 \mathrm{H}), 7.09(\mathrm{t}, J=8.2 \mathrm{~Hz}, 1 \mathrm{H}), 7.17(\mathrm{dd}, J=$ 8.2 and $2.0 \mathrm{~Hz}, 1 \mathrm{H}), 7.42(\mathrm{~m}, 2 \mathrm{H}), 10.0(\mathrm{~s}, 1 \mathrm{H})$. MS (ESI): $[\mathrm{M}+1]^{+}=299.1$.

5.1.3.14. (E)-3-(3-aminophenyl)-N-(3,5-dimethoxyphenyl)acrylamide (7n): Following general procedure $\mathrm{B}$, the crude residue purified by crystallization from $\mathrm{Et}_{2} \mathrm{O}$ furnished $\mathbf{7 n}$ as a yellow solid. Yield $>95 \%, \mathrm{mp} 55-57{ }^{\circ} \mathrm{C} .{ }^{1} \mathrm{H}$ NMR $\left(200 \mathrm{MHz}, d_{6}\right.$-DMSO) $\delta: 3.86(\mathrm{~s}, 6 \mathrm{H})$, $5.12(\mathrm{bs}, 2 \mathrm{H}), 6.63(\mathrm{~m}, 2 \mathrm{H}), 6.70(\mathrm{~m}, 2 \mathrm{H}), 6.95(\mathrm{~m}, 3 \mathrm{H}), 7.12(\mathrm{t}, J=8.2 \mathrm{~Hz}, 1 \mathrm{H}), 7.36(\mathrm{~d}, J$ $=15.6 \mathrm{~Hz}, 1 \mathrm{H}), 10.1(\mathrm{~s}, 1 \mathrm{H})$. MS (ESI): $[\mathrm{M}+1]^{+}=299.2$.

5.1.3.15. (E)-3-(3-aminophenyl)-N-(3,4,5-trimethoxyphenyl)acryl-amide (7o): Following general procedure $\mathrm{B}$, the crude residue purified by flash chromatography, using EtOAc for elution, furnished 7o as a yellow solid. Yield $85 \%, \mathrm{mp} 78-80{ }^{\circ} \mathrm{C} .{ }^{1} \mathrm{H} \mathrm{NMR}\left(200 \mathrm{MHz}, d_{6^{-}}\right.$ DMSO) $\delta: 3.63$ (s, 3H), 3.75 (s, 6H), $5.25(\mathrm{bs}, 2 \mathrm{H}), 6.62(\mathrm{~m}, 2 \mathrm{H}), 6.72(\mathrm{~m}, 2 \mathrm{H}), 7.09(\mathrm{~m}$, $3 \mathrm{H}), 7.36(\mathrm{~d}, J=15.6 \mathrm{~Hz}, 1 \mathrm{H}), 10.1(\mathrm{~s}, 1 \mathrm{H})$. MS (ESI): $[\mathrm{M}+1]^{+}=328.6$.

\subsubsection{6. (E)-3-(3-aminophenyl)-N-(4-morpholinophenyl)acrylamide (7p): Following} general procedure $\mathrm{B}$, the crude residue purified by flash chromatography, using EtOAc for elution, furnished $\mathbf{7 p}$ as a yellow solid. Yield $75 \%$, mp 239-241 ${ }^{\circ} \mathrm{C} .{ }^{1} \mathrm{H} \mathrm{NMR}(200 \mathrm{MHz}$, 
$d_{6}$-DMSO) $\delta: 3.05$ (t. $\left.J=5.0 \mathrm{~Hz}, 4 \mathrm{H}\right), 3.74(\mathrm{t} . J=5.0 \mathrm{~Hz}, 4 \mathrm{H}), 5.22(\mathrm{bs}, 2 \mathrm{H}), 6.62(\mathrm{~d}, J=$ $9.6 \mathrm{~Hz}, 2 \mathrm{H}), 6.75(\mathrm{~m}, 3 \mathrm{H}), 6.89(\mathrm{~d}, J=9.6 \mathrm{~Hz}, 2 \mathrm{H}), 7.07(\mathrm{t}, J=9.0 \mathrm{~Hz}, 1 \mathrm{H}), 7.32(\mathrm{~d}, J=$ $15.6 \mathrm{~Hz}, 1 \mathrm{H}), 7.54(\mathrm{~d}, J=9.0 \mathrm{~Hz}, 1 \mathrm{H}), 9.98(\mathrm{~s}, 1 \mathrm{H}) . \mathrm{MS}(\mathrm{ESI}):[\mathrm{M}+1]^{+}=324.2$.

5.1.3.17. (E)-3-(4-aminophenyl)-N-(4-methoxyphenyl)acrylamide (7q): Following general procedure $\mathrm{B}$, the crude residue purified by flash chromatography, using EtOAc:petroleum ether 1:1 (v:v) for elution, furnished $\mathbf{7 q}$ as a yellow solid. Yield $68 \%$, mp 190-192 ${ }^{\circ} \mathrm{C} .{ }^{1} \mathrm{H}$ NMR $\left(200 \mathrm{MHz}, \mathrm{CDCl}_{3}\right) \delta: 3.72$ (s, 3H), 5.62 (bs, 2H), 6.39 (d, $J=15.6$ $\mathrm{Hz}, 1 \mathrm{H}), 6.55(\mathrm{~d}, J=8.6 \mathrm{~Hz}, 2 \mathrm{H}), 6.87(\mathrm{~d}, J=9.0 \mathrm{~Hz}, 2 \mathrm{H}), 7.26(\mathrm{~d}, J=8.6 \mathrm{~Hz}, 2 \mathrm{H}), 7.33$ (d, $J=15.6 \mathrm{~Hz}, 1 \mathrm{H}), 7.56(\mathrm{~d}, J=9.0 \mathrm{~Hz}, 2 \mathrm{H}), 9.81(\mathrm{~s}, 1 \mathrm{H}) . \mathrm{MS}(\mathrm{ESI}):[\mathrm{M}+1]^{+}=269.2$.

5.1.3.18. (E)-3-(4-aminophenyl)-N-(3,4,5-trimethoxyphenyl)acrylamide (7r): Following general procedure $\mathrm{B}$, the crude residue purified by flash chromatography, using EtOAc for elution, furnished $7 \mathbf{r}$ as a yellow solid. Yield $65 \%, \mathrm{mp} 86-88{ }^{\circ} \mathrm{C} .{ }^{1} \mathrm{H}$ NMR $(200 \mathrm{MHz}$, $\left.\mathrm{CDCl}_{3}\right) \delta: 3.80(\mathrm{~s}, 3 \mathrm{H}), 3.86(\mathrm{~s}, 6 \mathrm{H}), 5.98(\mathrm{~s}, 2 \mathrm{H}), 6.27(\mathrm{~d}, J=15.2 \mathrm{~Hz}, 1 \mathrm{H}), 6.64(\mathrm{~d}, J=8.6$ $\mathrm{Hz}, 2 \mathrm{H}), 6.93$ (bs, 2H), 7.33 (d, $J=8.6 \mathrm{~Hz}, 2 \mathrm{H}), 7.62$ (d, $J=15.2 \mathrm{~Hz}, 1 \mathrm{H}), 10.3$ (s, 1H). MS (ESI): $[\mathrm{M}+1]^{+}=329.2$.

5.1.4. General procedure $\mathbf{C}$ for the synthesis of compounds (4a-r)-To an icecooled solution of amino derivative $7 \mathbf{a}-\mathbf{r}(1.00 \mathrm{mmol})$ in dry DMF $(5.0 \mathrm{~mL})$ were added a mixture of EDCI (383 mg, $2.00 \mathrm{mmol})$ and a-bromoacrylic acid $(2.00 \mathrm{mmol}, 306 \mathrm{mg})$. The reaction mixture was stirred at room temperature for $18 \mathrm{~h}$ and then concentrated under reduced pressure. The residue was dissolved with a mixture of $\mathrm{CH}_{2} \mathrm{Cl}_{2}(15 \mathrm{~mL})$ and water (5 $\mathrm{mL})$, and the organic phase was washed with brine $(5 \mathrm{~mL})$, dried over $\mathrm{Na}_{2} \mathrm{SO}_{4}$ and evaporated to dryness in vacuo. The resulting crude residue was purified by column chromatography on silica gel.

5.1.4.1. $\mathbf{N}$-\{3-[(1E)-3-anilino-3-oxoprop-1-en-1-yl]phenyl\}-2-bromoacrylamide (4a): Following general procedure $\mathrm{C}$, the crude residue purified by flash chromatography, using EtOAc:petroleum ether 1:1 (v:v) for elution, furnished $\mathbf{4 a}$ as a white solid. Yield 63\%, mp $132-134{ }^{\circ} \mathrm{C} .{ }^{1} \mathrm{H}$ NMR $\left(400 \mathrm{MHz}, d_{6}\right.$-DMSO) $\delta: 6.34(\mathrm{~d}, J=3.2 \mathrm{~Hz}, 1 \mathrm{H}), 6.78(\mathrm{~d}, J=3.2$ $\mathrm{Hz}, 1 \mathrm{H}), 6.83(\mathrm{~d}, J=16.0 \mathrm{~Hz}, 1 \mathrm{H}), 7.07(\mathrm{t}, J=8.4 \mathrm{~Hz}, 1 \mathrm{H}), 7.36(\mathrm{~m}, 2 \mathrm{H}), 7.43(\mathrm{t}, J=8.0$ $\mathrm{Hz}, 2 \mathrm{H}), 7.53(\mathrm{~d}, J=16.0 \mathrm{~Hz}, 1 \mathrm{H}), 7.60(\mathrm{~d}, J=8.0 \mathrm{~Hz}, 1 \mathrm{H}), 7.69(\mathrm{dd}, J=8.0$ and $1.2 \mathrm{~Hz}$, $2 \mathrm{H}), 8.08(\mathrm{~d}, J=1.2 \mathrm{~Hz}, 1 \mathrm{H}), 10.3(\mathrm{~s}, 1 \mathrm{H}) .10 .4(\mathrm{~s}, 1 \mathrm{H}) .{ }^{13} \mathrm{C}$ NMR $\left(100 \mathrm{MHz}, d_{6}\right.$-DMSO) $\delta$ : 118.6, 119.1 (2C), 121.8, 122.6, 123.3, 124.4, 124.9, 126.1, 128.8 (2C), 129.4, 135.1, 138.9, 139.3 139.8, 161.2, 163.3. MS (ESI): $[\mathrm{M}]^{+}=370.5,[\mathrm{M}+3]^{+}=372.7$. Anal. calcd for $\mathrm{C}_{18} \mathrm{H}_{15} \mathrm{BrN}_{2} \mathrm{O}_{2}$ : C, 58.24; $\mathrm{H}, 4.07 ; \mathrm{N}, 7.55$; found: $\mathrm{C}, 58.01 ; \mathrm{H}, 3.88 ; \mathrm{N}, 7.38$.

5.1.4.2. 2-Bromo-N-(3-\{(1E)-3-oxo-3-[(naphthalen-1-yl)amino] prop-1-en-1-yl\}phenyl)acrylamide (4b): Following general procedure $\mathrm{C}$, the crude residue purified by flash chromatography, using EtOAc:petroleum ether 1:2 (v:v) for elution, furnished $\mathbf{4 b}$ as a yellow solid. Yield 48\%, mp 170-172 ${ }^{\circ} \mathrm{C} .{ }^{1} \mathrm{H}$ NMR (400 MHz, $d_{6}$-DMSO) $\delta: 6.36$ (d, $J=$ $3.2 \mathrm{~Hz}, 1 \mathrm{H}), 6.79(\mathrm{~d}, J=3.2 \mathrm{~Hz}, 1 \mathrm{H}), 6.95(\mathrm{~d}, J=15.6 \mathrm{~Hz}, 1 \mathrm{H}), 7.48(\mathrm{~m}, 4 \mathrm{H}), 7.64(\mathrm{~m}, 4 \mathrm{H})$, $7.72(\mathrm{~d}, J=9.2 \mathrm{~Hz}, 1 \mathrm{H}), 7.82(\mathrm{~d}, J=15.6 \mathrm{~Hz}, 1 \mathrm{H}), 8.11(\mathrm{~s}, 1 \mathrm{H}), 8.44(\mathrm{~d}, J=1.8 \mathrm{~Hz}, 1 \mathrm{H})$, $10.4(\mathrm{~s}, 1 \mathrm{H}) .10 .5$ (s, $1 \mathrm{H}) .{ }^{13} \mathrm{C} \mathrm{NMR}\left(100 \mathrm{MHz}, d_{6}\right.$-DMSO) $\delta: 115.2,118.6,119.8,121.8$, 
122.5, 124.3, 124.8, 125.0, 126.4, 126.6, 127.2, 127.4, 128.4, 129.3, 129.7, 133.3, 135.0, 136.7, 138.8, 139.9, 161.1, 163.5. MS (ESI): $[\mathrm{M}]^{+}=420.2,[\mathrm{M}+2]^{+}=422.5$. Anal. calcd for $\mathrm{C}_{22} \mathrm{H}_{17} \mathrm{BrN}_{2} \mathrm{O}_{2}$ : C, 62.72; H, 4.07; N, 6.65; found: C, 62.53; H, 3.92; N, 6.48 .

5.1.4.3. 2-Bromo-N-(3-\{(1E)-3-oxo-3-[(4-fluorophenyl)amino]prop-1-en-1-yl\}phenyl)acrylamide (4c): Following general procedure $\mathrm{C}$, the crude residue purified by flash chromatography, using EtOAc:petroleum ether 4:6 (v:v) for elution, furnished $\mathbf{4 c}$ as a yellow solid. Yield 66\%, mp 194-196 ${ }^{\circ} \mathrm{C} .{ }^{1} \mathrm{H}$ NMR (400 MHz, $d_{6}$-DMSO) $\delta: 6.34$ (d, $J=$ $3.2 \mathrm{~Hz}, 1 \mathrm{H}), 6.76(\mathrm{~d}, J=15.8 \mathrm{~Hz}, 1 \mathrm{H}), 6.78(\mathrm{~d}, J=3.2 \mathrm{~Hz}, 1 \mathrm{H}), 7.18(\mathrm{~m}, 2 \mathrm{H}), 7.39(\mathrm{~m}, 1 \mathrm{H})$, $7.51(\mathrm{~d}, J=15.6,1 \mathrm{H}), 7.59(\mathrm{~m}, 2 \mathrm{H}), 7.73(\mathrm{~m}, 2 \mathrm{H}), 8.08(\mathrm{~s}, 1 \mathrm{H}), 10.3(\mathrm{~s}, 1 \mathrm{H}) .10 .4$ (s, $1 \mathrm{H}) .{ }^{13} \mathrm{C}$ NMR (100 MHz, $d_{6}$-DMSO) $\delta: 115.2,115.6,118.6,120.8,120.9,121.9,122.4$, 124.4, 124.9, 126.1, 129.4, 135.1, 135.6, 138.9, 139.9, $155.7(J=249.5 \mathrm{~Hz}), 161.2,163.3$. MS (ESI): $[\mathrm{M}]^{+}=388.5,[\mathrm{M}+2]^{+}=390.6$. Anal. calcd for $\mathrm{C}_{18} \mathrm{H}_{14} \mathrm{BrFN}_{2} \mathrm{O}_{2}: \mathrm{C}, 55.55 ; \mathrm{H}$, 3.63; N, 7.20; found: C, 55.38; H, 3.47; N, 7.01 .

5.1.4.4. 2-Bromo-N-(3-\{(1E)-3-oxo-3-[(3-fluorophenyl)amino]prop-1-en-1-yl\}phenyl)acrylamide (4d): Following general procedure $\mathrm{C}$, the crude residue purified by flash chromatography, using EtOAc:petroleum ether 4:6 (v:v) for elution, furnished $\mathbf{4 d}$ as a yellow solid. Yield $52 \%, \mathrm{mp} 144-146{ }^{\circ} \mathrm{C} .{ }^{1} \mathrm{H}$ NMR (400 MHz, $d_{6}$-DMSO) $\delta: 6.34(\mathrm{~d}, J=$ $3.2 \mathrm{~Hz}, 1 \mathrm{H}), 6.78(\mathrm{~d}, J=3.2 \mathrm{~Hz}, 1 \mathrm{H}), 6.86(\mathrm{~d}, J=15.8 \mathrm{~Hz}, 1 \mathrm{H}), 6.94(\mathrm{~m}, 1 \mathrm{H}), 7.39(\mathrm{~m}, 4 \mathrm{H})$, $7.54(\mathrm{~d}, J=15.6 \mathrm{~Hz}, 1 \mathrm{H}), 7.58(\mathrm{~m}, 1 \mathrm{H}), 7.71(\mathrm{~m}, 1 \mathrm{H}), 8.09(\mathrm{~s}, 1 \mathrm{H}), 10.4(\mathrm{~s}, 1 \mathrm{H}) .10 .5(\mathrm{~s}$, $1 \mathrm{H}) .{ }^{13} \mathrm{C}$ NMR $\left(100 \mathrm{MHz}, d_{6}\right.$-DMSO) $\delta: 106.4,106.9,110.3,110.7,115.6,119.3,122.7$, $122.9,125.2,125.6,126.8,130.1,131.0,131.2,135.7,139.6,141.2,141.5,141.8,160.4(J=$ 239.5 Hz), 161.9, 164.4. MS (ESI): $[\mathrm{M}]^{+}=388.6,[\mathrm{M}+2]^{+}=390.6$. Anal. calcd for $\mathrm{C}_{18} \mathrm{H}_{14} \mathrm{BrFN}_{2} \mathrm{O}_{2}$ : C, 55.55; H, 3.63; N, 7.20; found: C, 55.9; H, 3.48; N, 7.05.

\subsubsection{2-Bromo-N-(3-\{(1E)-3-oxo-3-[(3,4-difluorophenyl)amino] prop-1-en-1-} yl phenyl)-acrylamide (4e): Following general procedure $\mathrm{C}$, the crude residue purified by flash chromatography, using EtOAc:petroleum ether 1:1 (v:v) for elution, furnished $4 \mathbf{e}$ as a white solid. Yield 52\%, mp $152-154{ }^{\circ} \mathrm{C} .{ }^{1} \mathrm{H}$ NMR (400 MHz, $d_{6}$-DMSO) $\delta: 6.34$ (d, $J=3.2$ $\mathrm{Hz}, 1 \mathrm{H}), 6.78(\mathrm{~m}, 2 \mathrm{H}), 7.40(\mathrm{~m}, 4 \mathrm{H}), 7.55(\mathrm{~d}, J=15.6,1 \mathrm{H}), 7.60(\mathrm{~m}, 1 \mathrm{H}), 7.92(\mathrm{~m}, 1 \mathrm{H})$, $8.10(\mathrm{~s}, 1 \mathrm{H}), 10.4(\mathrm{~s}, 1 \mathrm{H}) .10 .5(\mathrm{~s}, 1 \mathrm{H}) .{ }^{13} \mathrm{C}$ NMR $\left(100 \mathrm{MHz}, d_{6}\right.$-DMSO) $\delta: 108.0,108.2$, 115.5, 117.5, 117.6, 118.6, 122.0, 124.5, 124.9, 126.1, 129.4, 133.6 (d, $J=28.4$ Hz), 134.9, $136.3(\mathrm{~d}, J=28.4 \mathrm{~Hz}), 138.9,140.5,161.2,163.5$. MS (ESI): $[\mathrm{M}]^{+}=406.4,[\mathrm{M}+2]^{+}=408.6$. Anal. calcd for $\mathrm{C}_{18} \mathrm{H}_{13} \mathrm{BrF}_{2} \mathrm{~N}_{2} \mathrm{O}_{2}$ : C, 53.09; H, 3.22; N, 6.88; found: $\mathrm{C}, 52.88 ; \mathrm{H}, 3.01 ; \mathrm{N}$, 6.73 .

5.1.4.6. 2-Bromo-N-(3-\{(1E)-3-0xo-3-[(4-chlorophenyl)amino]prop-1-en-1-yl\}phenyl)acrylamide (4f): Following general procedure $\mathrm{C}$, the crude residue purified by flash chromatography, using ethyl acetate:petroleum ether 6:4 (v:v) for elution, furnished $\mathbf{4 f}$ as a yellow solid. Yield 51\%, mp 214-216 ${ }^{\circ} \mathrm{C} .{ }^{1} \mathrm{H}$ NMR (400 MHz, $d_{6}$-DMSO) $\delta: 6.34$ (d, $J=$ $3.2 \mathrm{~Hz}, 1 \mathrm{H}), 6.78(\mathrm{~d}, J=3.2 \mathrm{~Hz}, 1 \mathrm{H}), 6.80(\mathrm{~d}, J=15.6 \mathrm{~Hz}, 1 \mathrm{H}), 7.39(\mathrm{~m}, 4 \mathrm{H}), 7.52(\mathrm{~m}, 2 \mathrm{H})$, $7.76(\mathrm{~d}, J=9.0 \mathrm{~Hz}, 2 \mathrm{H}), 8.12(\mathrm{~s}, 1 \mathrm{H}), 10.4(\mathrm{~s}, 1 \mathrm{H}) .10 .5(\mathrm{~s}, 1 \mathrm{H}) .{ }^{13} \mathrm{C}$ NMR $\left(100 \mathrm{MHz}, d_{\sigma^{-}}\right.$ DMSO) $\delta$ : 118.6, 120.7 (2C), 121.9, 122.3, 124.5, 124.9, 126.1, 126.9, 128.7 (2C), 129.4, 
135.0, 138.2, 138.9, 140.2, 161.2, 163.5. MS (ESI): $[\mathrm{M}+1]^{+}=404.9,[\mathrm{M}+3]^{+}=406.7$. Anal. calcd for $\mathrm{C}_{18} \mathrm{H}_{14} \mathrm{BrClN}_{2} \mathrm{O}_{2}$ : C, 53.29; H, 3.48; N, 6.91; found: C, 53.02; H, 3.22; N, 6.74.

5.1.4.7. 2-Bromo-N-(3-\{(1E)-3-oxo-3-[(p-tolyl)amino]prop-1-en-1-yl\}phenyl)acrylamide (4g): Following general procedure $\mathrm{C}$, the crude residue purified by flash chromatography, using EtOAc:petroleum ether 6:4 (v:v) for elution, furnished $\mathbf{4 g}$ as a white solid. Yield 66\%, mp 198-200 ${ }^{\circ} \mathrm{C}$. ${ }^{1} \mathrm{H}$ NMR (400 MHz, $d_{6}$-DMSO) $\delta: 2.27$ (s, 3H), 6.34 (d, $J=3.4 \mathrm{~Hz}, 1 \mathrm{H}), 6.78(\mathrm{~d}, J=3.4 \mathrm{~Hz}, 1 \mathrm{H}), 6.86(\mathrm{~d}, J=15.8 \mathrm{~Hz}, 1 \mathrm{H}), 7.12$ (d, $J=8.4 \mathrm{~Hz}, 2 \mathrm{H})$, $7.43(\mathrm{~m}, 3 \mathrm{H}), 7.56(\mathrm{~s}, 1 \mathrm{H}), 7.61(\mathrm{~d}, J=8.4 \mathrm{~Hz}, 2 \mathrm{H}), 8.07(\mathrm{~s}, 1 \mathrm{H}), 10.2(\mathrm{~s}, 1 \mathrm{H}) .10 .4$ (s, $1 \mathrm{H}) .{ }^{13} \mathrm{C}$ NMR $\left(100 \mathrm{MHz}, d_{6}\right.$-DMSO) $\delta: 20.9,119.0,119.6$ (2C), 122.2, 123.2, 124.8 , 125.4, 126.6, 129.6 (2C), 129.9, 132.8, 135.7, 137.2, 139.3, 140.0, 161.6, 163.6. MS (ESI): $[\mathrm{M}]^{+}=384.6,[\mathrm{M}+2]^{+}=386.6$. Anal. calcd for $\mathrm{C}_{19} \mathrm{H}_{17} \mathrm{BrN}_{2} \mathrm{O}_{2}: \mathrm{C}, 59.23 ; \mathrm{H}, 4.45 ; \mathrm{N}, 7.27$; found: C, 59.02; H, 4.31; N, 7.14.

5.1.4.8. 2-Bromo-N-(3-\{(1E)-3-[(4-methylbenzyl)amino]-3-oxoprop-1-en-1yl\}phenyl)acrylamide (4h): Following general procedure $\mathrm{C}$, the crude residue purified by flash chromatography, using EtOAc:petroleum ether 6:4 (v:v) for elution, furnished $\mathbf{4 h}$ as a white solid. Yield 53\%, mp 180-182 ${ }^{\circ} \mathrm{C} .{ }^{1} \mathrm{H}$ NMR (400 MHz, $d_{6}$-DMSO) $\delta: 2.28$ (s, 3H), $4.37(\mathrm{~d}, J=5.6 \mathrm{~Hz}, 2 \mathrm{H}), 6.32(\mathrm{~d}, J=3.2 \mathrm{~Hz}, 1 \mathrm{H}), 6.63(\mathrm{~d}, J=15.8 \mathrm{~Hz}, 1 \mathrm{H}), 6.76$ (d, $J=3.2$ $\mathrm{Hz}, 1 \mathrm{H}), 7.17$ (m, 4H), $7.46(\mathrm{~m}, 3 \mathrm{H}), 7.58$ (d, J=8.4 Hz, 1H), 7.95 (s, 1H), 8.63 (t, $J=5.6$ $\mathrm{Hz}, 1 \mathrm{H}), 10.3$ (s, 1H). ${ }^{13} \mathrm{C}$ NMR (100 MHz, $d_{6}$-DMSO) $\delta: 20.6,41.9,118.6,121.4,122.4$, 123.9, 124.8, 126.0, 127.2 (2C), 128.8 (2C), 129.2, 135.2, 135.8, 136.2, 138.5, 138.7, 161.0, 164.6. MS (ESI): $[\mathrm{M}]^{+}=398.4,[\mathrm{M}+2]^{+}=400.6$. Anal. calcd for $\mathrm{C}_{20} \mathrm{H}_{19} \mathrm{BrN}_{2} \mathrm{O}_{2}: \mathrm{C}, 60.16$; H, 4.80; N, 7.02; found: C, 59.92; H, 4.72; N, 6.88.

\subsubsection{2-Bromo-N-(3-\{(1E)-3-oxo-3-[(4-methoxyphenyl)amino] prop-1-en-1-} yl\}phenyl)-acrylamide (4i): Following general procedure $\mathrm{C}$, the crude residue purified by flash chromatography, using EtOAc:petroleum ether 6:4 (v:v) for elution, furnished $\mathbf{4 i}$ as a white solid. Yield 52\%, mp 193-195 ${ }^{\circ} \mathrm{C} .{ }^{1} \mathrm{H}$ NMR (400 MHz, $d_{6}$-DMSO) $\delta: 3.73$ (s, 3H), $6.34(\mathrm{~d}, J=3.2 \mathrm{~Hz}, 1 \mathrm{H}), 6.78(\mathrm{~m}, 2 \mathrm{H}), 6.89(\mathrm{~d}, J=9.0 \mathrm{~Hz}, 2 \mathrm{H}), 7.37(\mathrm{~m}, 2 \mathrm{H}), 7.42(\mathrm{~d}, J=$ $15.8 \mathrm{~Hz}, 1 \mathrm{H}), 7.58(\mathrm{~m}, 3 \mathrm{H}), 8.06(\mathrm{~s}, 1 \mathrm{H}), 10.2(\mathrm{~s}, 1 \mathrm{H}) .10 .4(\mathrm{~s}, 1 \mathrm{H}) .{ }^{13} \mathrm{C} \mathrm{NMR}(100 \mathrm{MHz}$, $d_{6^{-D M S O}}$ ) : 55.4, 114.2 (2C), 119.7, 121.1, 121.8 (2C), 121.9, 124.3, 127.1, 128.6, 128.7, 134.7, 137.2, 139.0, 140.2, 155.4, 161.4, 163.5. MS (ESI): $[\mathrm{M}]^{+}=400.5,[\mathrm{M}+2]^{+}=402.7$. Anal. calcd for $\mathrm{C}_{19} \mathrm{H}_{17} \mathrm{BrN}_{2} \mathrm{O}_{3}$ : C, 56.87; H, 4.27; N, 6.98; found: C, 56.75; H, 4.13; N, 6.78 .

5.1.4.10. 2-Bromo-N-(4-\{(1E)-3-oxo-3-[(4-ethoxyphenyl)amino] prop-1-en-1-yl $\}$ phenyl)acrylamide (4j): Following general procedure $C$, the crude residue purified by flash chromatography, using EtOAc:petroleum ether $1: 1(\mathrm{v}: \mathrm{v})$ for elution, furnished $\mathbf{4 j}$ as a white solid. Yield 54\%, mp 201-203 ${ }^{\circ} \mathrm{C} .{ }^{1} \mathrm{H}$ NMR (400 MHz, $d_{6}$-DMSO) $\delta: 1.31$ (t, $J=7.2 \mathrm{~Hz}$, $3 \mathrm{H}), 3.98(\mathrm{q}, J=7.2 \mathrm{~Hz}, 2 \mathrm{H}), 6.33(\mathrm{~d}, J=3.2 \mathrm{~Hz}, 1 \mathrm{H}), 6.78(\mathrm{~d}, J=3.2 \mathrm{~Hz}, 1 \mathrm{H}), 6.82(\mathrm{~d}, J=$ $15.5 \mathrm{~Hz}, 1 \mathrm{H}), 6.88(\mathrm{~d}, J=8.8 \mathrm{~Hz}, 2 \mathrm{H}), 7.37$ (d, $J=8.0 \mathrm{~Hz}, 1 \mathrm{H}), 7.44(\mathrm{t}, J=8.0 \mathrm{~Hz}, 1 \mathrm{H})$, $7.53(\mathrm{~d}, J=15.6 \mathrm{~Hz}, 1 \mathrm{H}), 7.59(\mathrm{~m}, 3 \mathrm{H}), 8.06(\mathrm{~s}, 1 \mathrm{H}), 10.1(\mathrm{~s}, 1 \mathrm{H}) .10 .4(\mathrm{~s}, 1 \mathrm{H}) .{ }^{13} \mathrm{C} \mathrm{NMR}$ (100 MHz, $d_{6}$-DMSO) $\delta: 14.7,63.1,114.5$ (2C), 118.5, 120.6 (2C), 121.7, 122.8, 124.3, $124.9,126.1,129.4,132.3,135.2,138.8,139.3,154.6,161.2,162.9 . \mathrm{MS}(\mathrm{ESI}):[\mathrm{M}]^{+}=$ 
414.6, $[\mathrm{M}+2]^{+}=416.5$. Anal. calcd for $\mathrm{C}_{20} \mathrm{H}_{19} \mathrm{BrN}_{2} \mathrm{O}_{3}$ : C, 57.84; $\mathrm{H}, 4.61 ; \mathrm{N}, 6.75$; found: C, 57.74; H, 4.47; N, 6.58 .

5.1.4.11. 2-Bromo-N-(3-\{(1E)-3-0xo-3-[(4-trifluoromethoxyphenyl) amino]prop-1-en-1yl $\}$ phenyl)-acrylamide (4k): Following general procedure $\mathrm{C}$, the crude residue purified by flash chromatography, using EtOAc:petroleum ether 6:4 (v:v) for elution, furnished $\mathbf{4 k}$ as a white solid. Yield $48 \%$, mp 126-128 ${ }^{\circ} \mathrm{C} .{ }^{1} \mathrm{H}$ NMR (400 MHz, $d_{6}$-DMSO) $\delta: 6.34$ (d, $J=3.2$ $\mathrm{Hz}, 1 \mathrm{H}), 6.86(\mathrm{~m}, 2 \mathrm{H}), 6.89(\mathrm{~d}, J=9.0 \mathrm{~Hz}, 2 \mathrm{H}), 7.39(\mathrm{~m}, 2 \mathrm{H}), 7.54(\mathrm{~m}, 2 \mathrm{H}), 7.84(\mathrm{~d}, J=8.8$ $\mathrm{Hz}, 2 \mathrm{H}), 8.09$ (s, 1H), 10.4 (s, 1H). 10.5 (s, 1H). ${ }^{13} \mathrm{C}$ NMR (100 MHz, $d_{6}$-DMSO) $\delta: 118.6$, 120.5 (2C), 121.7 (2C), 121.9, 122.2, 124.5, 124.9, 126.1, 129.4, 135.0, 138.5, 138.9, 140.3, 143.6, 161.2, 183.5. MS (ESI): $[\mathrm{M}]^{+}=454.5,[\mathrm{M}+2]^{+}=456.7$. Anal. calcd for $\mathrm{C}_{19} \mathrm{H}_{14} \mathrm{BrF}_{3} \mathrm{~N}_{2} \mathrm{O}_{3}$ : C, 50.13; H, 3.10; N, 6.15; found: $\mathrm{C}, 49.94 ; \mathrm{H}, 0.97 ; \mathrm{N}, 6.01$.

5.1.4.12. 2-Bromo-N-(3-\{(1E)-3-0x0-3-[(4-(trifluoromethylthio) phenyl)amino]prop-1en-1-yl\}phenyl)-acrylamide (41): Following general procedure $C$, the crude residue purified by flash chromatography, using EtOAc:petroleum ether 6:4 (v:v) for elution, furnished $\mathbf{4 l}$ as a white solid. Yield 58\%, mp $125-127{ }^{\circ} \mathrm{C} .{ }^{1} \mathrm{H}$ NMR (400 MHz, $d_{6}$-DMSO) $\delta: 6.34(\mathrm{~d}, J=$ $3.0 \mathrm{~Hz}, 1 \mathrm{H}), 6.78(\mathrm{~d}, J=3.0 \mathrm{~Hz}, 1 \mathrm{H}), 6.88(\mathrm{~d}, J=15.6 \mathrm{~Hz}, 1 \mathrm{H}), 7.44(\mathrm{~m}, 2 \mathrm{H}), 7.56(\mathrm{~m}, 2 \mathrm{H})$, $7.67(\mathrm{~d}, J=8.6 \mathrm{~Hz}, 2 \mathrm{H}), 7.88(\mathrm{~d}, J=8.6 \mathrm{~Hz}, 2 \mathrm{H}), 8.11(\mathrm{~s}, 1 \mathrm{H}), 10.4(\mathrm{~s}, 1 \mathrm{H}) .10 .6(\mathrm{~s}$, $1 \mathrm{H}) .{ }^{13} \mathrm{C}$ NMR $\left(100 \mathrm{MHz}, d_{6}\right.$-DMSO) $\delta: 115.9,118.5,119.9$ (2C), 121.9, 124.5, 124.8 , 126.0, 128.0, 129.3, 134.8, 137.3 (2C), 138.8, 140.7, 142.1, 161.1, 163.7. MS (ESI): [M+1] ${ }^{+}$ $=470.8,[\mathrm{M}+3]^{+}=472.7$. Anal. calcd for $\mathrm{C}_{19} \mathrm{H}_{14} \mathrm{BrF}_{3} \mathrm{~N}_{2} \mathrm{O}_{2} \mathrm{~S}: \mathrm{C}, 48.42 ; \mathrm{H}, 2.99 ; \mathrm{N}, 5.94$; found: $\mathrm{C}, 48.21 ; \mathrm{H}, 2.77 ; \mathrm{N}, 5.78$.

\subsubsection{2-Bromo-N-(3-\{(1E)-3-oxo-3-[(3,4-dimethoxyphenyl) amino]prop-1-en-1-} yl\}phenyl)-acrylamide (4m): Following general procedure $C$, the crude residue purified by flash chromatography, using EtOAc:petroleum ether 7:3 (v:v) for elution, furnished $\mathbf{4 m}$ as a yellow solid. Yield $78 \%, \mathrm{mp} 108-110{ }^{\circ} \mathrm{C} .{ }^{1} \mathrm{H}$ NMR (400 MHz, $d_{6}$-DMSO) $\delta: 3.73(\mathrm{~s}, 3 \mathrm{H}$ ), $3.75(\mathrm{~s}, 3 \mathrm{H}), 6.34(\mathrm{~d}, J=3.2 \mathrm{~Hz}, 1 \mathrm{H}), 6.79(\mathrm{~m}, 3 \mathrm{H}), 6.90(\mathrm{~d}, J=8.6 \mathrm{~Hz}, 1 \mathrm{H}), 7.20$ (dd, $J=$ 8.6 and $2.6 \mathrm{~Hz}, 1 \mathrm{H}), 7.43(\mathrm{~m}, 3 \mathrm{H}), 7.54(\mathrm{dd}, J=8.2$ and $2.2 \mathrm{~Hz}, 1 \mathrm{H}), 8.11(\mathrm{~d}, J=2.2 \mathrm{~Hz}$, $1 \mathrm{H}), 10.1(\mathrm{~s}, 1 \mathrm{H}) .10 .4(\mathrm{~s}, 1 \mathrm{H}) .{ }^{13} \mathrm{C}$ NMR (100 MHz, $d_{6}$-DMSO) $\delta: 55.2,55.6,104.2,111.0$, 112.0, 118.5, 121.7, 122.7, 124.2, 124.8, 126.0, 129.3, 132.8, 135.1, 138.8, 139.3, 144.9, 148.5, 161.1, 162.9. MS (ESI): $[\mathrm{M}]^{+}=430.6,[\mathrm{M}+2]^{+}=432.7$. Anal. calcd for $\mathrm{C}_{20} \mathrm{H}_{19} \mathrm{BrN}_{2} \mathrm{O}_{4}$ : C, 55.70; H, 4.44; N, 6.50; found: C, 55.55; H, 4.21; N, 6.34 .

\subsubsection{2-Bromo-N-(3-\{(1E)-3-oxo-3-[(3,5-dimethoxyphenyl) amino]prop-1-en-1-} yl phenyl)-acrylamide (4n): Following general procedure $C$, the crude residue purified by flash chromatography, using ethyl acetate:petroleum ether 1:1 (v:v) for elution, furnished $\mathbf{4 n}$ as a yellow solid. Yield 52\%, mp 91-93 ${ }^{\circ} \mathrm{C} .{ }^{1} \mathrm{H}$ NMR (400 MHz, $d_{6}$-DMSO) $\delta: 3.73(\mathrm{~s}, 6 \mathrm{H})$, $6.24(\mathrm{t}, J=2.4 \mathrm{~Hz}, 1 \mathrm{H}), 6.33(\mathrm{~d}, J=3.2 \mathrm{~Hz}, 1 \mathrm{H}), 6.76(\mathrm{~d}, J=15.8 \mathrm{~Hz}, 1 \mathrm{H}), 6.78(\mathrm{~d}, J=3.2$ $\mathrm{Hz}, 1 \mathrm{H}), 6.94(\mathrm{~d}, J=2.4 \mathrm{~Hz}, 2 \mathrm{H}), 7.38(\mathrm{~m}, 2 \mathrm{H}), 7.49(\mathrm{~d}, J=15.8 \mathrm{~Hz}, 1 \mathrm{H}), 7.57(\mathrm{~m}, 1 \mathrm{H})$, $8.08(\mathrm{~s}, 1 \mathrm{H}), 10.2$ (s, 1H). 10.4 (s, 1H). ${ }^{13} \mathrm{C}$ NMR (100 MHz, $d_{6}$-DMSO) $\delta: 55.0$ (2C), 95.4, 97.5 (2C), 118.6, 121.9, 122.6, 124.4, 124.9, 126.1, 129.4, 135.1, 138.9, 140.0, 140.8, 160.5 (2C), 161.2, 163.4. MS (ESI): $[\mathrm{M}]^{+}=430.6,[\mathrm{M}+2]^{+}=432.7$. Anal. calcd for $\mathrm{C}_{20} \mathrm{H}_{19} \mathrm{BrN}_{2} \mathrm{O}_{4}$ : C, 55.70; H, 4.44; N, 6.50; found: C, 55.48; H, 4.18; N, 6.30 . 
5.1.4.15. 2-Bromo-N-(3-\{(1E)-3-oxo-3-[(3,4,5-trimethoxyphenyl) amino]prop-1-en-1yl\}phenyl)-acrylamide (40): Following general procedure $\mathrm{C}$, the crude residue purified by flash chromatography, using EtOAc:petroleum ether 7:3 (v:v) for elution, furnished 40 as a yellow solid. Yield 70\%, mp 93-95 ${ }^{\circ} \mathrm{C} .{ }^{1} \mathrm{H}$ NMR (400 MHz, $d_{6}$-DMSO) $\delta: 3.63(\mathrm{~s}, 3 \mathrm{H})$, $3.77(\mathrm{~s}, 6 \mathrm{H}), 6.34(\mathrm{~d}, J=3.2 \mathrm{~Hz}, 1 \mathrm{H}), 6.79(\mathrm{~m}, 2 \mathrm{H}), 7.09(\mathrm{~s}, 2 \mathrm{H}), 7.37(\mathrm{~m}, 2 \mathrm{H}), 7.49(\mathrm{~d}, J=$ $15.8 \mathrm{~Hz}, 1 \mathrm{H}), 7.58(\mathrm{~d}, J=7.8 \mathrm{~Hz}, 1 \mathrm{H}), 8.07(\mathrm{~s}, 1 \mathrm{H}), 10.2$ (s, 1H). 10.4 (s, $1 \mathrm{H}) .{ }^{13} \mathrm{C}$ NMR (100 MHz, $d_{6}$-DMSO) $\delta: 55.6$ (2C), 60.0, 96.8 (2C), 118.6, 121.7, 122.5, 124.2, 124.8, 126.0, 129.3, 133.4, 135.0, 135.3, 138.8, 139.6, 152.6 (2C), 161.1, 163.1. MS (ESI): [M] ${ }^{+}=$ 460.7, $[\mathrm{M}+2]^{+}=462.9$. Anal. calcd for $\mathrm{C}_{21} \mathrm{H}_{21} \mathrm{BrN}_{2} \mathrm{O}_{5}$ : C, 54.68; $\mathrm{H}, 4.59 ; \mathrm{N}, 6.07$; found: C, 54.56; H, 4.42; N, 5.88.

\subsubsection{2-Bromo-N-(3-\{(1E)-3-oxo-3-[(4-morpholinophenyl)amino] prop-1-en-1-} yl $\}$ phenyl)-acrylamide (4p): Following general procedure $\mathrm{C}$, the crude residue purified by flash chromatography, using ethyl acetate for elution, furnished $4 \mathbf{p}$ as a yellow solid. Yield $53 \%$, mp 210-212 ${ }^{\circ} \mathrm{C} .{ }^{1} \mathrm{H}$ NMR (400 MHz, $d_{6}$-DMSO) $\delta: 3.06$ (t. $\left.J=5.2 \mathrm{~Hz}, 4 \mathrm{H}\right), 3.72$ (t. $J$ $=4.8 \mathrm{~Hz}, 4 \mathrm{H}), 6.34(\mathrm{~d}, J=3.2 \mathrm{~Hz}, 1 \mathrm{H}), 6.78(\mathrm{~d}, J=3.2 \mathrm{~Hz}, 1 \mathrm{H}), 6.82(\mathrm{~d}, J=16.0 \mathrm{~Hz}, 1 \mathrm{H})$, $6.94(\mathrm{~d}, J=9.6 \mathrm{~Hz}, 2 \mathrm{H}), 7.36(\mathrm{~d}, J=7.6 \mathrm{~Hz}, 1 \mathrm{H}), 7.42(\mathrm{t}, J=7.6 \mathrm{~Hz}, 1 \mathrm{H}), 7.52(\mathrm{~d}, J=16.0$ $\mathrm{Hz}, 1 \mathrm{H}), 7.57$ (m, 3H), 8.06 (s, 1H), $10.1(\mathrm{~s}, 1 \mathrm{H}) .10 .4$ (s, 1H). ${ }^{13} \mathrm{C}$ NMR $\left(100 \mathrm{MHz}, d_{6^{-}}\right.$ DMSO) 8: 48.7 (2C), 66.0 (2C), 115.4 (2C), 118.5, 120.1 (2C), 121.6, 122.8, 124.2, 124.8, 126.0, 129.3 131.4, 135.2, 138.7, 139.0, 147.2, 161.0, 162.6. MS (ESI): $[\mathrm{M}+1]^{+}=455.8$, $[\mathrm{M}+3]^{+}=457.9$. Anal. calcd for $\mathrm{C}_{22} \mathrm{H}_{22} \mathrm{BrN}_{3} \mathrm{O}_{3}: \mathrm{C}, 57.90 ; \mathrm{H}, 4.86 ; \mathrm{N}, 9.21$; found: $\mathrm{C}$, $57.69 ; \mathrm{H}, 4.73 ; \mathrm{N}, 9.01$.

\subsubsection{2-Bromo-N-(4-\{(1E)-3-oxo-3-[(4-methoxyphenyl)amino] prop-1-en-1-} yl phenyl)-acrylamide (4q): Following general procedure $C$, the crude residue purified by flash chromatography, using EtOAc:petroleum ether 1:1 (v:v) for elution, furnished $\mathbf{4 q}$ as a cream-colored solid. Yield 53\%, mp 219-221 ${ }^{\circ} \mathrm{C} .{ }^{1} \mathrm{H}$ NMR (400 MHz, $d_{6}$-DMSO) $\delta: 3.73$ (s, 3H), $6.33(\mathrm{~d}, J=3.2 \mathrm{~Hz}, 1 \mathrm{H}), 6.64(\mathrm{~d}, J=15.8 \mathrm{~Hz}, 1 \mathrm{H}), 6.77(\mathrm{~d}, J=3.2 \mathrm{~Hz}, 1 \mathrm{H}), 6.90(\mathrm{~d}$, $J=8.8 \mathrm{~Hz}, 2 \mathrm{H}), 7.49(\mathrm{~d}, J=15.8 \mathrm{~Hz}, 1 \mathrm{H}), 7.61(\mathrm{~m}, 4 \mathrm{H}), 7.72(\mathrm{~d}, J=8.8 \mathrm{~Hz}, 2 \mathrm{H}), 10.0(\mathrm{~s}$, 1H). $10.4(\mathrm{~s}, 1 \mathrm{H}) .{ }^{13} \mathrm{C}$ NMR (100 MHz, $d_{6}$-DMSO) $\delta: 55.6,114.4(2 \mathrm{C}), 120.9(2 \mathrm{C}), 121.1$ (2C), 121.8, 125.3, 126.6, 128.7 (2C), 131.1, 133.0, 139.5, 140.0, 155.7, 161.6, 163.6. MS (ESI): $[\mathrm{M}]^{+}=400.8,[\mathrm{M}+2]^{+}=402.9$. Anal. calcd for $\mathrm{C}_{19} \mathrm{H}_{17} \mathrm{BrN}_{2} \mathrm{O}_{3}: \mathrm{C}, 56.87 ; \mathrm{H}, 4.27 ; \mathrm{N}$, 6.98; found: C, $56.67 ; \mathrm{H}, 4.11 ; \mathrm{N}, 6.64$.

\subsubsection{2-Bromo-N-(4-\{(1E)-3-0x0-3-[(3,4,5-trimethoxyphenyl) amino]prop-1-en-1-} yl\}phenyl-acrylamide (4r): Following general procedure $\mathrm{C}$, the crude residue purified by flash chromatography, using EtOAc:petroleum ether 1:1 (v:v) for elution, furnished $\mathbf{4 r}$ as a yellow solid. Yield 62\%, mp 93-95 ${ }^{\circ} \mathrm{C} .{ }^{1} \mathrm{H}$ NMR (400 MHz, $d_{6}$-DMSO) $\delta: 3.71(\mathrm{~s}, 3 \mathrm{H})$, $3.76(\mathrm{~s}, 6 \mathrm{H}), 6.33(\mathrm{~d}, J=3.2 \mathrm{~Hz}, 1 \mathrm{H}), 6.74(\mathrm{~d}, J=3.2 \mathrm{~Hz}, 1 \mathrm{H}), 6.77(\mathrm{~d}, J=15.2 \mathrm{~Hz}, 1 \mathrm{H})$, 7.09 (s, 2H), $7.43(\mathrm{~d}, J=15.2 \mathrm{~Hz}, 1 \mathrm{H}), 7.58(\mathrm{~d}, J=8.8 \mathrm{~Hz}, 2 \mathrm{H}), 7.72(\mathrm{~d}, J=8.8 \mathrm{~Hz}, 2 \mathrm{H})$, $10.1(\mathrm{~s}, 1 \mathrm{H}) .10 .4(\mathrm{~s}, 1 \mathrm{H}) .{ }^{13} \mathrm{C}$ NMR $\left(100 \mathrm{MHz}, d_{6}\right.$-DMSO) $\delta$ : $55.6(2 \mathrm{C}), 60.0,96.9(2 \mathrm{C})$, 120.4 (2C), 121.0, 124.7, 126.0, 128.2 (2C), 130.4, 133.5, 135.3, 139.4, 139.6, $152.6(2 \mathrm{C})$, 161.0, 163.4. MS (ESI): $[\mathrm{M}]^{+}=460.7,[\mathrm{M}+2]^{+}=462.8$. Anal. calcd for $\mathrm{C}_{21} \mathrm{H}_{21} \mathrm{BrN}_{2} \mathrm{O}_{5}: \mathrm{C}$, $54.68 ; \mathrm{H}, 4.59 ; \mathrm{N}, 6.07$; found: $\mathrm{C}, 54.5 ; \mathrm{H}, 4.38 ; \mathrm{N}, 5.92$. 


\subsection{Biological assays}

5.2.1. Cell growth inhibitory activity-Human T-cell leukemia (Jurkat and CEM) and acute B-cell lymphoblastic leukemia (SEM) cells were grown in RPMI-1640 medium (Gibco Milano Italy). Human cervix carcinoma (HeLa), breast adenocarcinoma (MCF-7) and colon adenocarcinoma (HT-29 and LoVo) cells were grown in DMEM medium (Gibco, Milano, Italy). Both media were supplemented with 115 units $/ \mathrm{mL}$ of penicillin $\mathrm{G}$ (Gibco, Milano, Italy), $115 \mu \mathrm{g} / \mathrm{mL}$ streptomycin (Invitrogen, Milano, Italy) and $10 \%$ fetal bovine serum (Invitrogen, Milano, Italy). $\mathrm{CEM}^{\mathrm{Vbl}-100}$ cells are a multidrug-resistant line selected against vinblastine [32] and were grown in complete RPMI 1640 medium supplemented with vinblastine $100 \mathrm{ng} / \mathrm{mL}$. LoVo Doxo cells are a doxorubicin resistant subclone of LoVo cells [33] and were grown in complete Ham's F12 medium supplemented with doxorubicin $(0.1 \mu \mathrm{g} / \mathrm{mL})$. Individual wells of a 96 -well tissue culture microtiter plate were inoculated with $100 \mu \mathrm{L}$ of complete medium containing $8 \times 10^{3}$ cells. The plates were incubated at 37 ${ }^{\circ} \mathrm{C}$ in a humidified $5 \% \mathrm{CO}_{2}$ incubator for $18 \mathrm{~h}$ prior to the experiments. Stock solutions (10 $\mathrm{mM}$ ) of the different compounds were obtained by dissolving them in DMSO. After medium removal, $100 \mu \mathrm{L}$ of the drug solution, dissolved in complete medium at different concentrations, was added to each well and incubated at $37{ }^{\circ} \mathrm{C}$ for $72 \mathrm{~h}$. The percentage of DMSO in the medium never exceeded $0.25 \%$. This was also the maximum DMSO concentration in all cell-based assays described below. Cell viability was measured by the (3-(4,5-dimethylthiazol-2-yl)-2,5-diphenyl tetrazolium bromide (MTT)) assay as previously described [48]. The IC50 was defined as the compound concentration required to inhibit cell proliferation by $50 \%$. Some experiments were performed in the presence of different scavengers, such as BHA, GSH, TOC, DTT or NAC, all purchased from Sigma-Aldrich (Milano, Italy).

\subsubsection{Cell growth inhibitory activity in peripheral blood mononuclear cells (PBMC)—PBMC from healthy donors were obtained by separation on Lymphoprep} (Fresenius KABI Norge AS) gradient. After extensive washing, cells were resuspended (1.0 $\times 10^{6}$ cells $/ \mathrm{mL}$ ) in RPMI-1640 with $10 \%$ fetal bovine serum and incubated overnight. For cytotoxicity evaluations in proliferating PBL cultures, non-adherent cells were resuspended at $5 \times 10^{5}$ cells $/ \mathrm{mL}$ in growth medium, containing $2.5 \mu \mathrm{g} / \mathrm{mL}$ PHA (Irvine Scientific).

Different concentrations of the test compounds were added, and viability was determined 72 $\mathrm{h}$ later by the MTT test. For cytotoxicity evaluations in resting PBMC cultures, non-adherent cells were resuspended $\left(5 \times 10^{5}\right.$ cells $\left./ \mathrm{mL}\right)$ and treated for $72 \mathrm{~h}$ with the test compounds, as described above.

\subsubsection{Effects on tubulin polymerization and on colchicine binding to tubulin-}

Bovine brain tubulin was purified as described previously [33]. To evaluate the effect of the compounds on tubulin assembly in vitro [49], varying concentrations were preincubated with $10 \mu \mathrm{M}$ tubulin in glutamate buffer at $30^{\circ} \mathrm{C}$ and then cooled to $0{ }^{\circ} \mathrm{C}$. After addition of GTP, the mixtures were transferred to $0{ }^{\circ} \mathrm{C}$ cuvettes in a recording spectrophotometer and warmed to $30{ }^{\circ} \mathrm{C}$, and the assembly of tubulin was observed turbidimetrically.

5.2.4. Immunofluorescence analysis-Cells were fixed in cold $4 \%$ formaldehyde for $15 \mathrm{~min}$, rinsed and stored prior to analysis. Primary antibody staining was performed for $\beta$ - 
tubulin (mouse, monoclonal 1:1000, Sigma-Aldrich, Milano, Italy). After incubation, cells were washed and incubated with an Alexa conjugated secondary antibody (1:2000, Life Technologies, Monza, Italy). Cells were counterstained with 4',6-diamidin-2-phenylindole (DAPI) (1:10,000, Sigma-Aldrich, Milano, Italy). Images were obtained on a videoconfocal microscope (Vico, Eclipse Ti80, Nikon), equipped with a digital camera.

5.2.5. Annexin-V assay-Surface exposure of phosphatidylserine on apoptotic cells was measured by flow cytometry with a Coulter Cytomics FC500 (Beckman Coulter) by adding Annexin-V-FITC to cells according to the manufacturer's instructions (Annexin-V Fluos, Roche Diagnostic). Simultaneously the cells were stained with PI. Excitation was set at 488 $\mathrm{nm}$, and the emission filters were set at $525 \mathrm{~nm}$ and $585 \mathrm{~nm}$ for FITC and DAPI, respectively.

5.2.6. Flow cytometric analysis of cell cycle distribution-For flow cytometric analysis of DNA content, $2.5 \times 10^{5}$ Hela cells in exponential growth were treated with different concentrations of the test compounds for 24 and $48 \mathrm{~h}$. After an incubation period, the cells were collected, centrifuged and fixed with ice-cold ethanol (70\%). The cells were then treated with lysis buffer containing RNAse A and $0.1 \%$ Triton X-100, and then stained with PI. Samples were analyzed on a Cytomic FC500 flow cytometer (Beckman Coulter). DNA histograms were analyzed using MultiCycle for Windows (Phoenix Flow Systems).

\subsubsection{Assessment of mitochondrial changes and ROS production-The} mitochondrial membrane potential was measured with the lipophilic cation JC-1 (Molecular Probes, Eugene, OR, USA), while the production of ROS was followed by flow cytometry using the fluorescent dyes HE (Molecular Probes) and $\mathrm{H}_{2}$ DCFDA (Molecular Probes), as previously described [50].

\subsubsection{Detection of the intracellular GSH content-Cellular GSH levels were} analyzed using CMFDA (Molecular Probes) [42]. Cells were treated with the test compound for different times. Cells were harvested, centrifuged and incubated in the presence of a solution of $5 \mu \mathrm{M} \mathrm{CMFDA}$ at $37^{\circ} \mathrm{C}$ for $30 \mathrm{~min}$. Cytoplasmic esterases convert nonfluorescent CMFDA to fluorescent 6-chloromethylfluorescein, which can then react with GSH. Fluorescence intensity was determined by flow cytometry.

5.2.9. Western blot analysis-Aliquots of HeLa cell cultures, both control and containing the desired compounds at the indicated concentrations, were removed at time points as indicated. The cells were collected by centrifugation and washed twice with phosphate-buffered saline chilled to $0{ }^{\circ} \mathrm{C}$. The cells were then suspended in a lysis buffer at $0{ }^{\circ} \mathrm{C}$ for $30 \mathrm{~min}$. The resulting suspensions were clarified by centrifugation $(15000 \times g, 4$ ${ }^{\circ} \mathrm{C}, 10 \mathrm{~min}$ ) and the protein concentrations of the supernatants determined with the BCA protein kit (Pierce, Italy). Protein aliquots of $20 \mu \mathrm{g}$ were subjected to sodium-dodecyl sulfate-polyacrylamide gel electrophoresis using $7.5-15 \%$ gradient polyacrylamide gels. Proteins were then electroblotted to PVDF Hybond-p membranes from GE Healthcare, Milano, Italy. The membranes were then treated with ECL Blocking Agent from GE Healthcare, using a rotary shaker at $4{ }^{\circ} \mathrm{C}$, as instructed by the manufacturer. Membranes were next incubated for $2 \mathrm{~h}$ at room temperature with a variety of primary antibodies from 
Cell Signaling, Alexis, Upstate, and Sigma-Aldrich, as indicated in the individual experiments. Finally, membranes were incubated with peroxidase-labeled secondary antibodies for $60 \mathrm{~min}$. All membranes were visualized using ECL Select (GE Healthcare) and exposed to Hyperlm MP (GE Healthcare). To ensure equal protein loading, each membrane was stripped and reprobed with an anti- $\beta$-actin antibody.

5.2.10. Statistical analysis-Statistical significance of differences between means of control and treated samples were calculated using Student's $t$-test. $P$ values $<$ of 0.05 were considered significant.

\section{Acknowledgments}

The authors gratefully acknowledged Alberto Casolari for his excellent technical assistance.

\section{References}

1. Junior CV, Danuello A, Bolzani VdS, Barreiro EJ, Fraga CAM. Curr Med Chem. 2007; 14:1829_ 1852. [PubMed: 17627520]

2. Gediya LK, Njar VC. Expert Opin Drug Discov. 2009; 4:1099-1111. [PubMed: 23480431]

3. Duan YC, Zheng YC, Li XC, Wang MM, Ye XW, Guan YY, Liu GZ, Zheng JX, Liu HM. Eur J Med Chem. 2013; 64:99-110. [PubMed: 23644193]

4. Decker M. Curr Med Chem. 2011; 18:1464-1475. [PubMed: 21428895]

5. Tsogoeva SB. Mini-Rev Med Chem. 2010; 10:773-793. [PubMed: 20105118]

6. Meunier B. Acc Chem Res. 2008; 41:69-77. [PubMed: 17665872]

7. Muregi FW, Kirira PG, Ishih A. Curr Med Chem. 2011; 18:113-143. [PubMed: 21110811]

8. Mayur YC, Peters GJ, Prasad VV, Lemo C, Sathish NK. Curr Cancer Drug Targets. 2009; 9:298306. [PubMed: 19442050]

9. Solomon VR, Hu C, Lee H. Bioorg Med Chem. 2010; 18:1563-1572. [PubMed: 20106668]

10. Zou HB, Dong SY, Zhou CX, Hu LH, Wu YH, Li HB, Gong JX, Sun LL, Wu XM, Bai H, Fan BT, Hao XJ, Stöckigt J, Zhao Y. Bioorg Med Chem. 2006; 14:2060-2071. [PubMed: 16303311]

11. Qian Y, Zhang HJ, Zhang H, Xu C, Zhao J, Zhu HL. Bioorg Med Chem. 2010; 18:4991-4996. [PubMed: 20594859]

12. Dallavalle S, Cincinelli R, Nannei R, Merlini L, Morini G, Penco S, Pisano C, Vesci L, Barbarino M, Zuco V, Cesare MD, Zunino F. Eur J Med Chem. 2009; 44:1900-1912. [PubMed: 19084294]

13. Zou H, Wu H, Zhang X, Zhao Y, Stöckigt J, Lou Y, Yu Y. Bioorg Med Chem. 2010; 18:63516359. [PubMed: 20673727]

14. Luo Y, Qiu KM, Lu X, Liu K, Fu J, Zhu HL. Bioorg Med Chem. 2011; 19:4730-4738. [PubMed: 21783370]

15. Meydan N, Grunberger T, Dadi H, Shahar M, Arpaia E, Lapidot Z, Leeder JS, Freedman M, Cohen A, Gazit A, Levitzki A, Roifman CM. Nature. 1996; 379:645-648. [PubMed: 8628398]

16. Shin DS, Kim J, Han DC, Son KH, Lee CW, Kim HM, Hong SH, Kwon BM. Bioorg Med Chem Lett. 2007; 17:5423-5427. [PubMed: 17683933]

17. Nam NH, You YJ, Kim Y, Hong DH, Kim HM, Han BZ. Bioorg Med Chem Lett. 2001; 11:11731176. [PubMed: 11354370]

18. Dothager RS, Putt KS, Allen BJ, Leslie BJ, Nesterenko V, Hergenrother PJ. J Am Chem Soc. 2005; 127:8686-8696. [PubMed: 15954774]

19. Leslie BJ, Holaday CR, Nguyen T, Hergenrother PJ. J Med Chem. 2010; 53:3964-3972. [PubMed: 20411988]

20. Raffa D, Maggio B, Plescia F, Cascioferro S, Plescia S, Raimondi MV, Daidone G, Tolomeo M, Grimaudo S, Di Cristina A, Pipitone RM, Bai R, Hamel E. Eur J Med Chem. 2011; 46:2786-2796. [PubMed: 21530013] 
21. Marchini S, Broggini M, Sessa C, D’Incalci M. Expert Opin Investig Drugs. 2001; 10:1703-1714.

22. Lorusso D, Mainenti S, Pietragalla A, Ferrandina G, Foco G, Masciullo V, Scambia G. Expert Opin Investig Drugs. 2009; 18:1939-1946.

23. Leahy M, Ray-Coquard I, Verwei J, Le Cesne A, Duffaud F, Hogendoorn PC, Fowst C, De Balincourt C, Di Paola ED, Van Glabbeke M, Judson I, Blay JY. Eur J Cancer. 2007; 43:308-315. [PubMed: 17095209]

24. Romagnoli R, Baraldi PG, Cruz-Lopez O, Lopez-Cara C, Preti D. Mini-Rev Med Chem. 2009; 9:81-94. [PubMed: 19149662]

25. Ahn B, Sok S. Curr Pharm Des. 1996; 2:247-262.

26. Das U, Sharma RK, Dimmock JR. Curr Med Chem. 2009; 16:2001-2020. [PubMed: 19519378]

27. Pati HN, Das U, Kawase M, Sakagami H, Balzarini J, De Clercq E, Dimmock JR. Bioorg Med Chem. 2008; 16:5747-5753. [PubMed: 18397829]

28. Vishnoi S, Agrawl V, Kasana VK. J Agric Food Chem. 2009; 57:3261-3265. [PubMed: 19368353]

29. Szakács G, Paterson JK, Ludwig JA, Booth-Genthe C, Gottesman MM. Nat Rev Drug Discov. 2006; 5:219-234. [PubMed: 16518375]

30. Baguley BC. Mol Biotechnol. 2010; 46:308-316. [PubMed: 20717753]

31. Toffoli S, Viel G, Tuimoto A, Bisconti I, Rossi G, Baoiocchi G. Br J Cancer. 1991; 63:51-56. [PubMed: 1671208]

32. Dupuis M, Flego M, Molinari A, Cianfruglia M. HIV Med. 2003; 4:338-345. [PubMed: 14525546]

33. Hamel E, Lin CM. Biochemistry. 1984; 23:4173-4184. [PubMed: 6487596]

34. Vermes I, Haanen C, Steffens-Nakken H, Reutelingsperger C. J Immunol Methods. 1995; 184:39_ 51. [PubMed: 7622868]

35. Li H, Zhou H, Xu C, Yua J. Cell. 1998; 94:491-501. [PubMed: 9727492]

36. Kantari C, Walczak H. Biochim Biophys Acta. 2011; 1813:558-563. [PubMed: 21295084]

37. Fernandez-Capetillo O, Lee A, Nussenzweig M, Nussenzweig A. DNA Repair. 2004; 3:959-967. [PubMed: 15279782]

38. a) Kamer I, Sarig R, Zaltsman Y, Niv H, Oberkovitz G, Regev L, Haimovich G, Lerenthal Y, Marcellus RC, Gross A. Cell. 2005; 122:593-603. [PubMed: 16122426] b) Zinkel SS, Hurov KE, Ong C, Abtahi FM, Gross A, Korsmeyer SJ. Cell. 2005; 122:579-591. [PubMed: 16122425]

39. Rothe G, Valet G. J Leukoc Biol. 1990; 47:440-448. [PubMed: 2159514]

40. Cossarizza A, Ferraresi R, Troiano L, Roat E, Gibellini L, Bertoncelli L, Nasi M, Pinti M. Nat Protoc. 2009; 4:1790-1797. [PubMed: 20010930]

41. Cai J, Jones DP. J Biol Chem. 1998; 273:11401-11404. [PubMed: 9565547]

42. Nohl H, Gille L, Staniek K. Biochem Pharmacol. 2005; 69:719-723. [PubMed: 15710349]

43. Hedley DW, Chow S. Cytometry. 1994; 15:349-358. [PubMed: 8026225]

44. Circu ML, Aw TY. Free Radic Res. 2008; 42:689-706. [PubMed: 18671159]

45. Lu SC. Mol Asp Med. 2009; 30:42-59.

46. Zucker B, Hanusch J, Bauer G. Cell Death Differ. 1997; 4:388-395. [PubMed: 16465257]

47. Beria I, Baraldi PG, Cozzi P, Caldarelli M, Geroni C, Marchini S, Mongelli N, Romagnoli R. J Med Chem. 2004; 47:2611-2623. [PubMed: 15115402]

48. Romagnoli R, Baraldi PG, Brancale A, Ricci A, Hamel E, Bortolozzi R, Basso G, Viola G. J Med Chem. 2011; 54:5144-5153. [PubMed: 21663319]

49. Hamel E. Cell Biochem Biophys. 2003; 38:1-21. [PubMed: 12663938]

50. Viola G, Bortolozzi R, Ferlin MG, Brun P, Castagliuolo I, Moro S, Hamel E, Basso G. Biochem Pharm. 2012; 83:16-26. [PubMed: 21964343] 


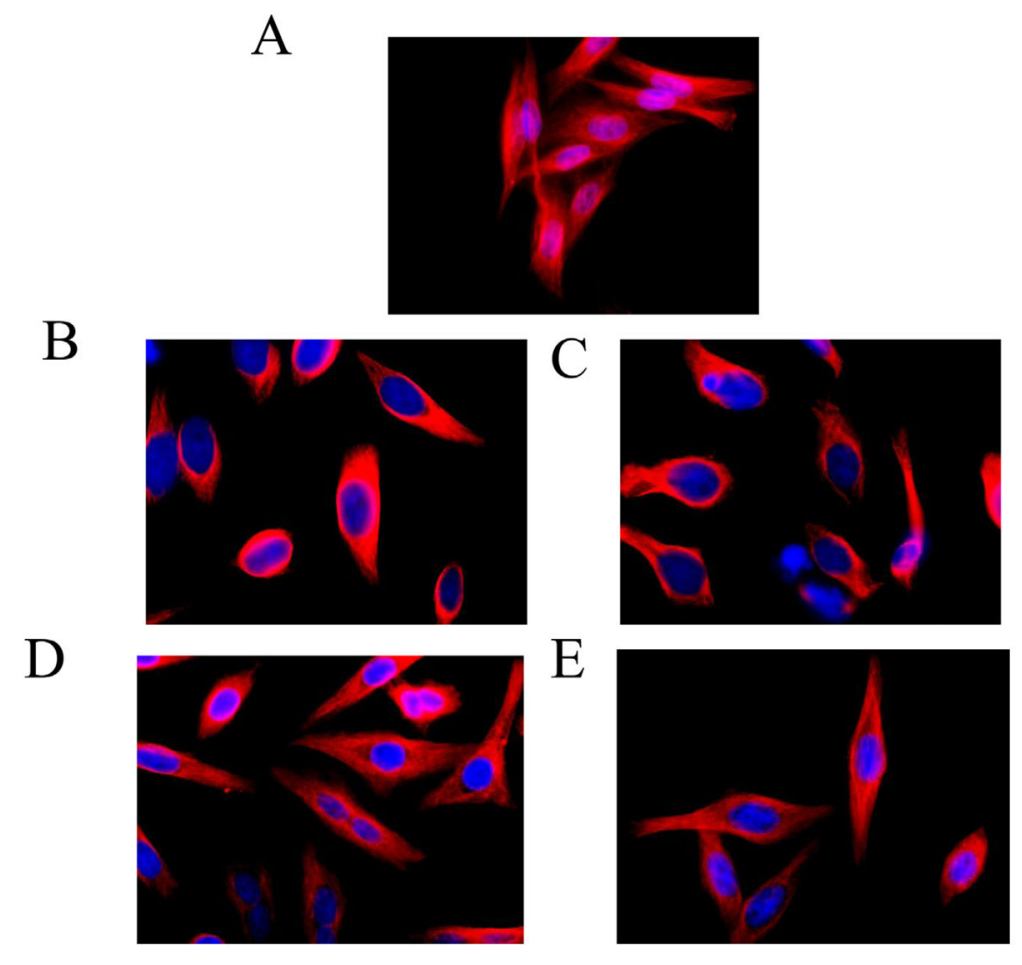

Fig. 1.

Effects of compounds $\mathbf{4 p}$ (panels B and C) and $\mathbf{4 r}$ (panels D and E) on microtubule networks in Hela cells. Panel A, untreated cells. Cells were incubated with $2.5 \mu \mathrm{M}$ (panels B and D) or $5.0 \mu \mathrm{M}$ (panels $\mathrm{C}$ and $\mathrm{E}$ ) of the compounds for $24 \mathrm{~h}$ and then stained with anti- $\beta$ tubulin primary antibody and secondary Alexa-conjugated antibody and then observed by confocal microscopy (magnification 20x). Cells were also counterstained with DAPI to visualize the nuclei. 

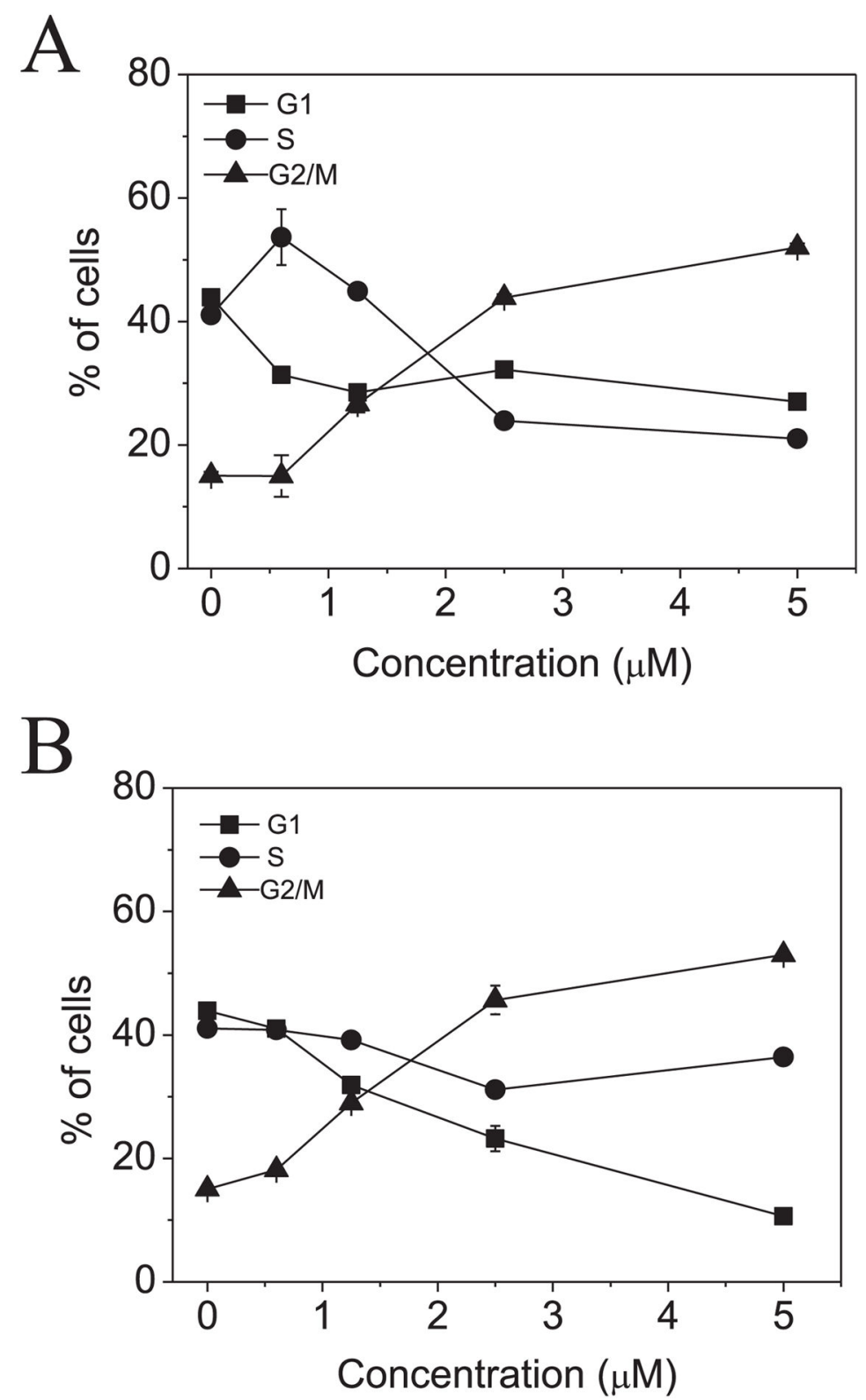

Fig. 2.

Percentage of cells in each phase of the cell cycle in HeLa cells treated with the 4r (Panel A) and $4 \mathbf{p}$ (Panel B) at the indicated concentrations for $24 \mathrm{~h}$. Cells were fixed and labeled with PI and analyzed by flow cytometry as described in the experimental section. 

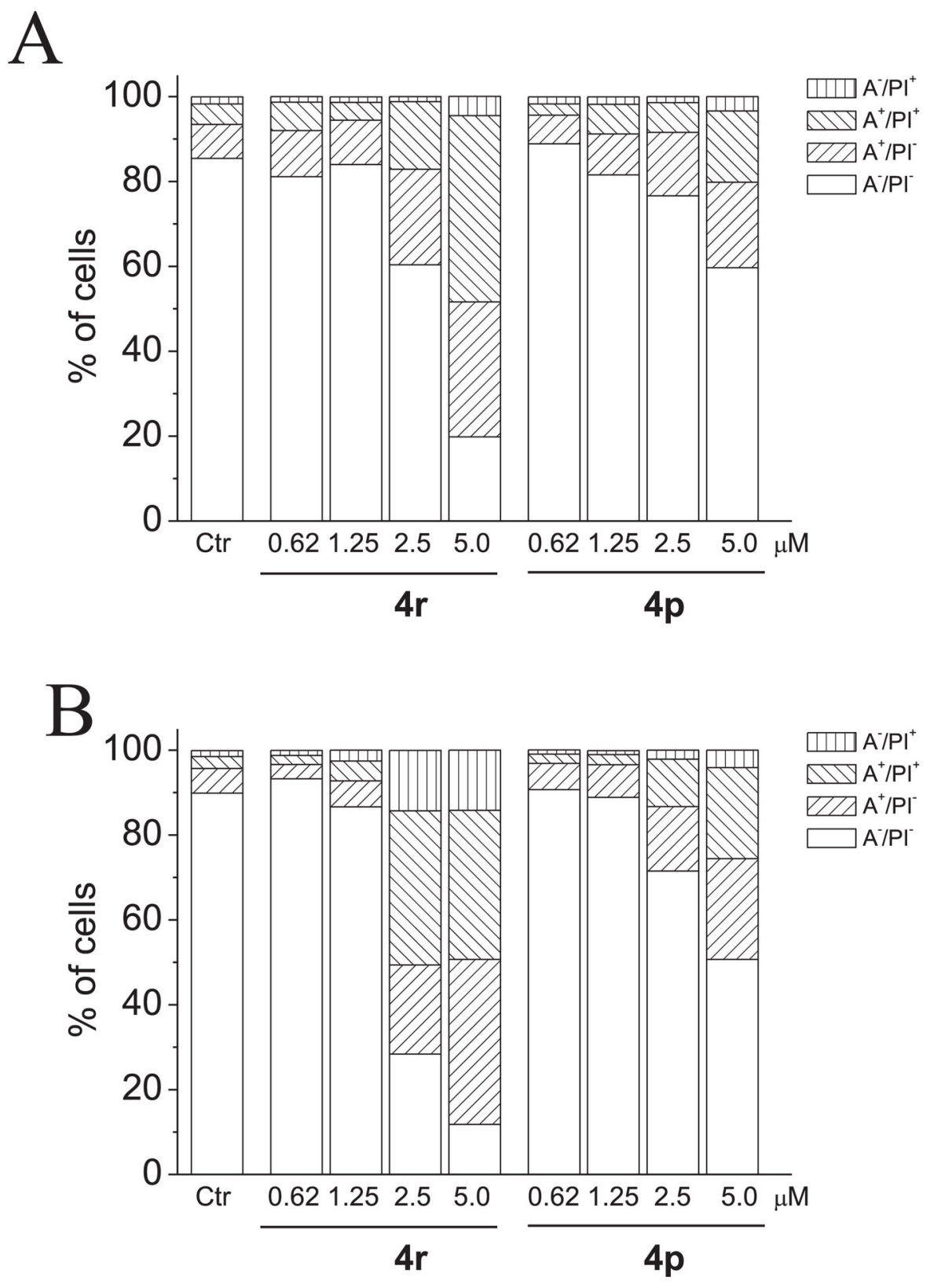

Fig. 3.

Flow cytometric analysis of apoptotic cells after treatment of HeLa cells with $4 \mathbf{r}$ (Panel A) or $4 \mathbf{p}$ (Panel B) at the indicated concentrations after incubation for 24 or $48 \mathrm{~h}$. The cells were harvested and labeled with annexin-V-FITC and PI and analyzed by flow cytometry. Data are represented as means of three independent experiments. For the sake of clarity, error bars were omitted. 


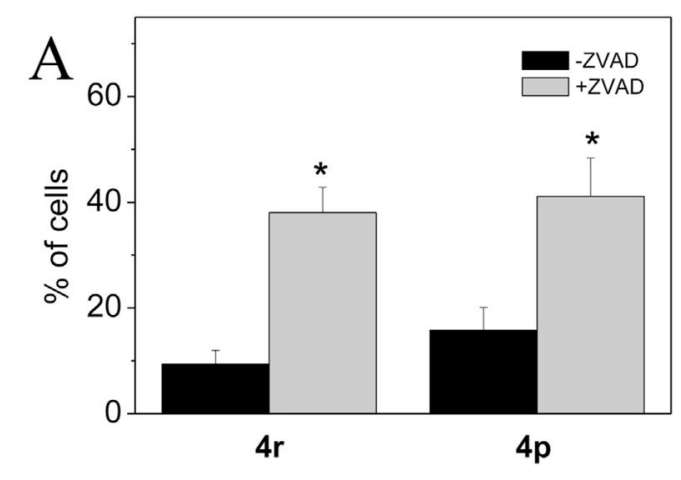

B

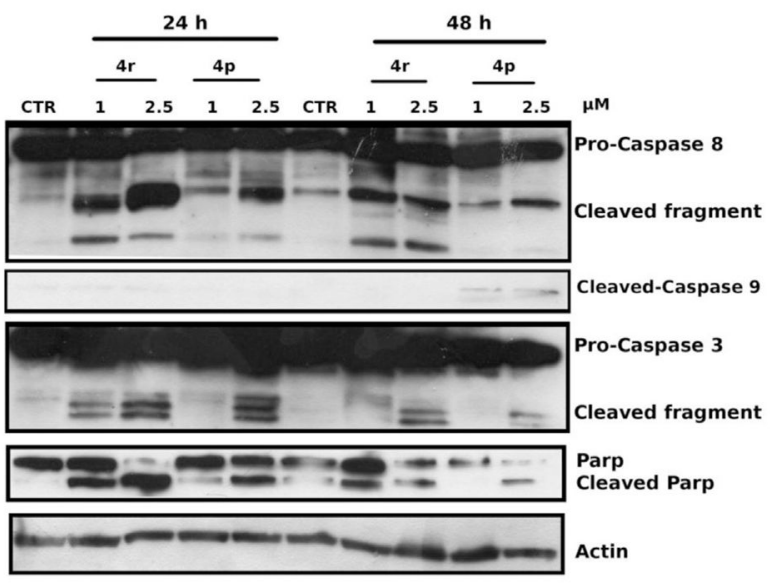

Fig. 4.

(A). Percentage of cell viability after a $48 \mathrm{~h}$ incubation of HeLa cells with $4 \mathbf{r}$ or $\mathbf{4 p}(2.5 \mu \mathrm{M})$ in the presence or in the absence of $z$-VAD.fmk $(100 \mu \mathrm{M})$. Means \pm SEM of three independent experiments. $* * P<0.01 v s$. $\mathbf{4 p}$ or $\mathbf{4 r}$ treated cells. (B). Western blot analysis of caspase-3, cleaved caspase-9, caspase-8 and PARP after treatment of HeLa cells with $4 \mathbf{r}$ or $4 \mathbf{p}$ at the indicated concentrations and for the indicated times. To confirm equal protein loading, each membrane was stripped and reprobed with anti- $\beta$-actin antibody. 


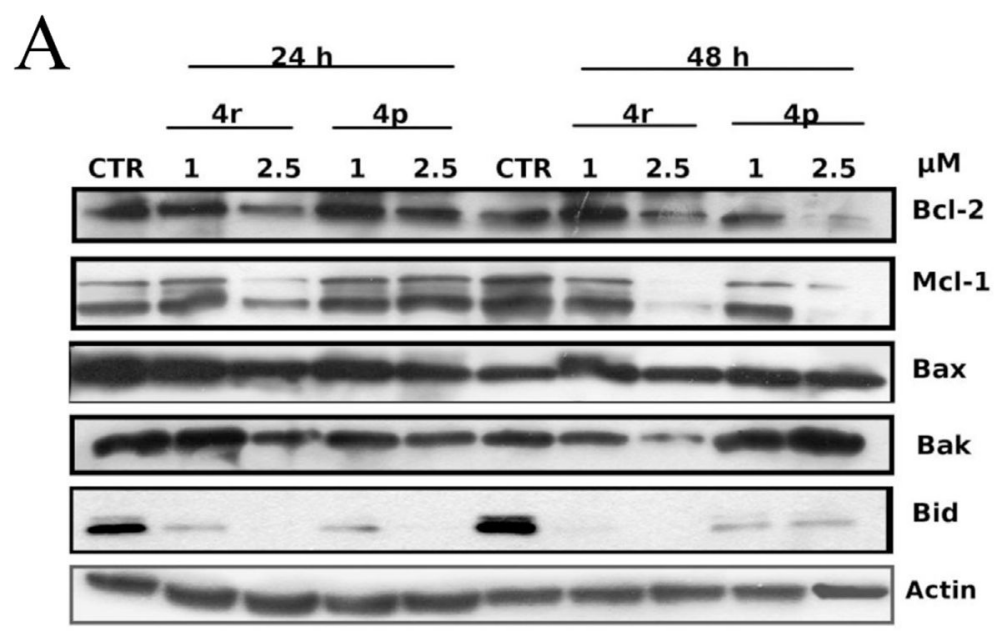

B

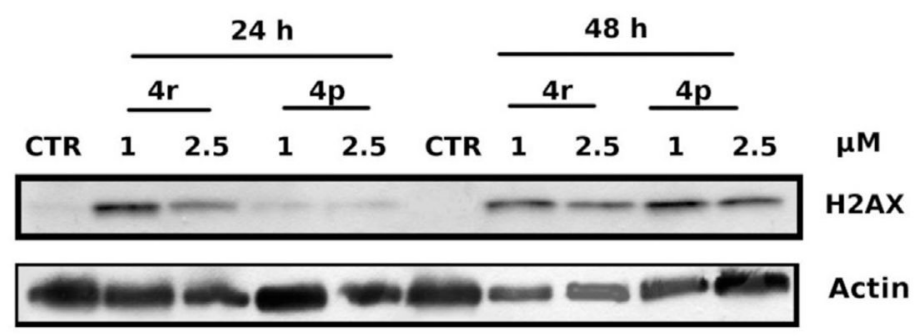

Fig. 5.

Western blot analysis of Bcl-2, Bax, Bak, Mcl-1and Bid (Panel A), and $\gamma \mathrm{H} 2 \mathrm{~A} . X$ (panel B) after treatment of Hela cells with $\mathbf{4 p}$ and $\mathbf{4 r}$ at the indicated concentrations and for the indicated times. To confirm equal protein loading, each membrane was stripped and reprobed with anti- $\beta$-actin antibody. 

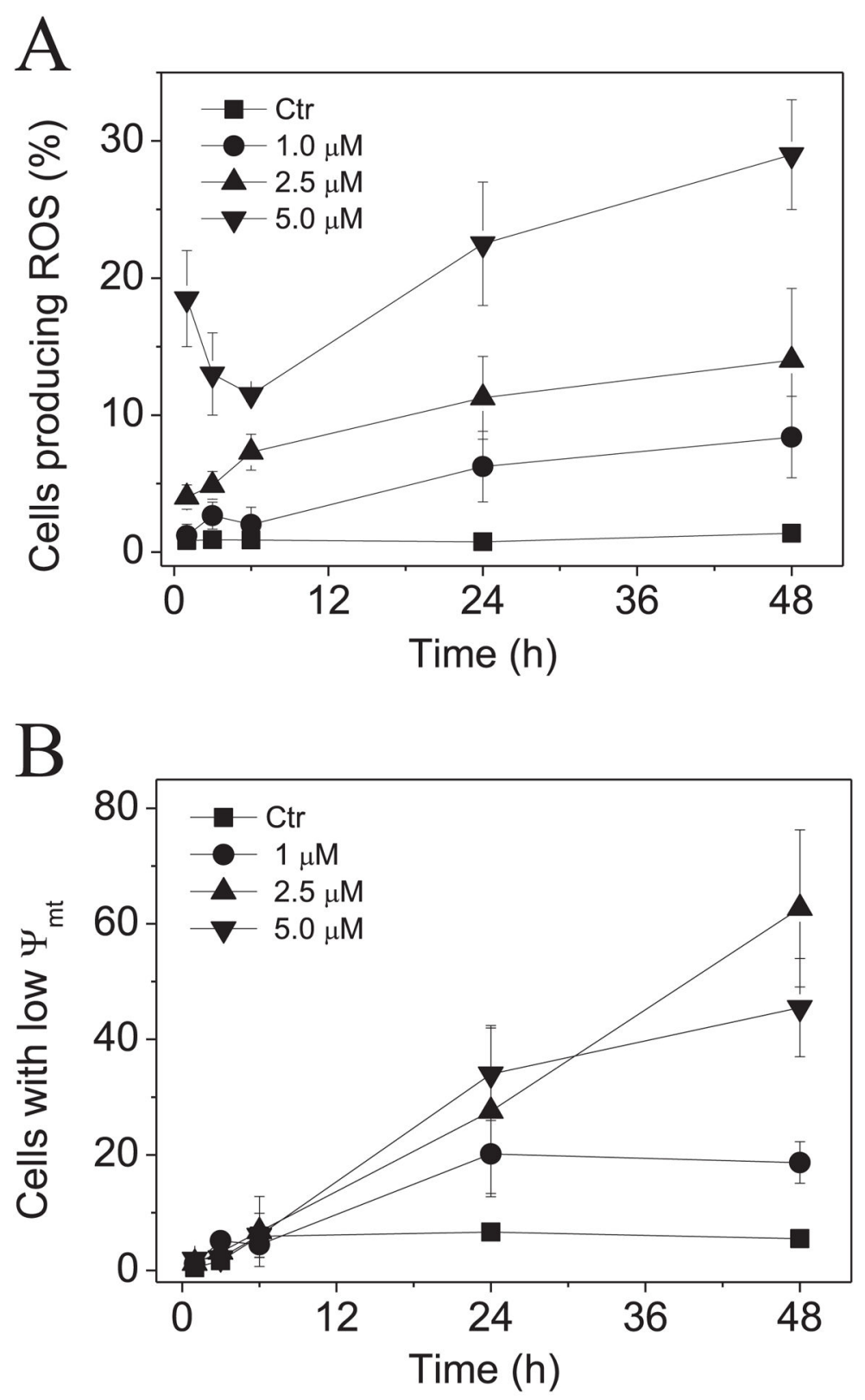

Fig. 6.

Production of ROS (Panel A) and assessment of mitochondrial membrane potential $\left(\Delta \psi_{\mathrm{mt}}\right)$ (Panel B) following treatment of HeLa cells with compound $\mathbf{4 r}$ at the indicated concentrations. A. Cells were stained with $\mathrm{H}_{2}$ DCFDA at the indicated times and analyzed by flow cytometry to measure production of ROS. B. The change in $\Delta \psi_{\mathrm{mt}}$ was measured by flow cytometry using JC-1 at the indicated times. 

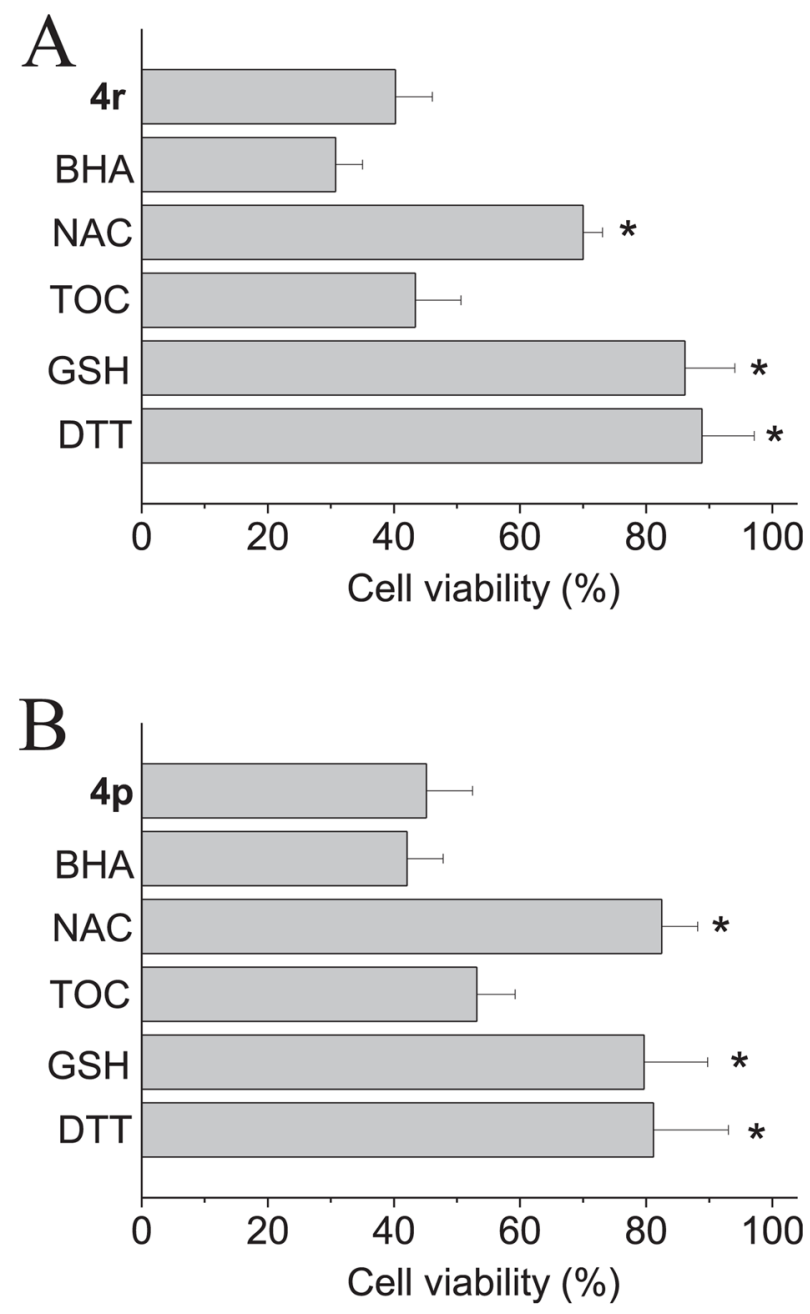

Fig. 7.

Effect of ROS scavengers on cell death induced by compounds $4 \mathbf{r}$ and $\mathbf{4 p}$. HeLa cells were treated with the two compounds at $2.5 \mu \mathrm{M}$ for $48 \mathrm{~h}$ in the presence of BHA $(10 \mu \mathrm{M})$ TOC $(100 \mu \mathrm{M}) \mathrm{NAC}(100 \mu \mathrm{M})$, GSH $(1 \mathrm{mM})$ or DTT $(1 \mathrm{mM})$. Cell viability was measured by the MTT assay. Data are represented as means \pm S.E.M. for four independent experiments. ${ }^{*} p<$ 0.01 vs compound alone. 

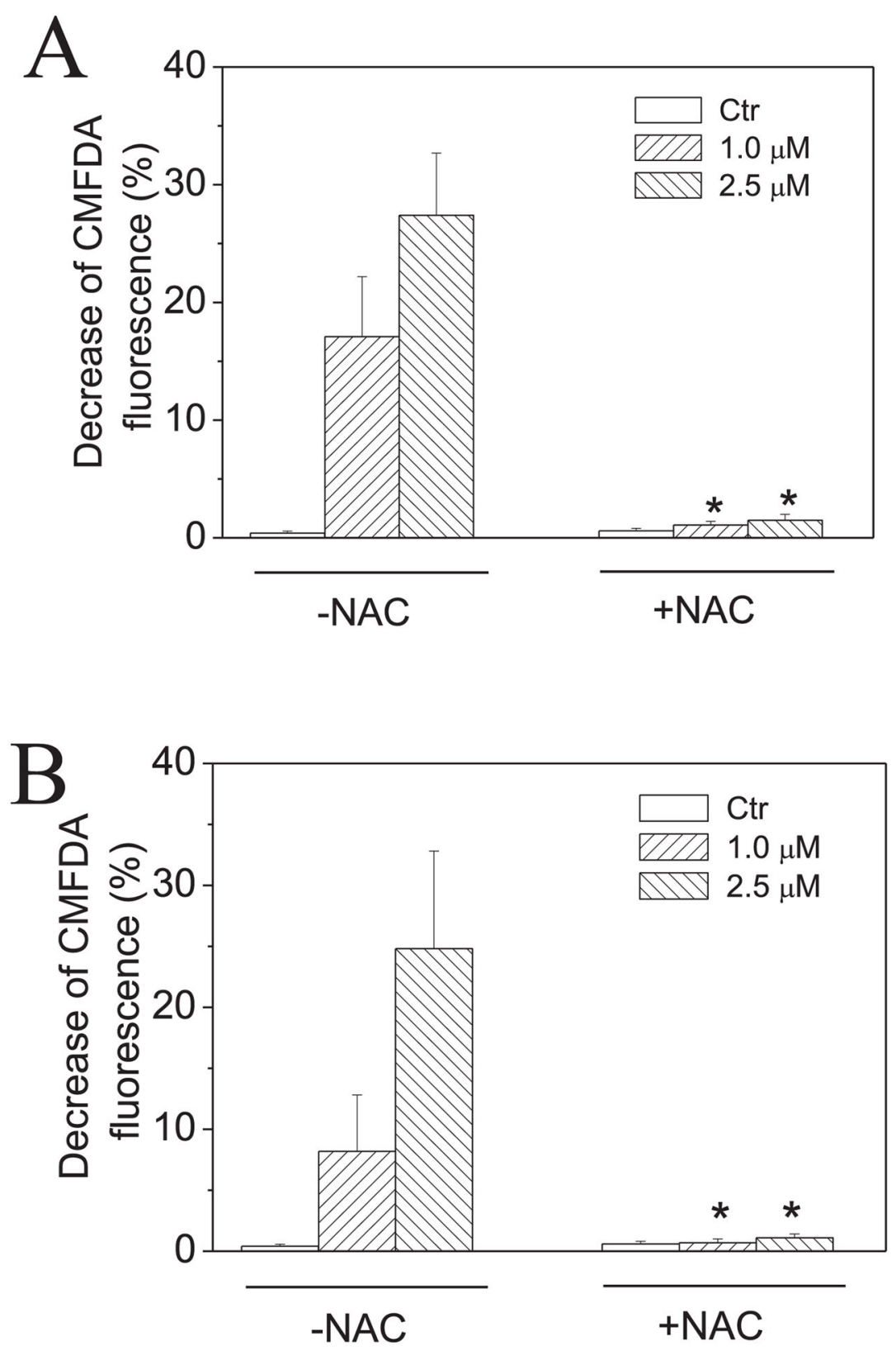

Fig. 8.

Compounds 4p (panel A) and 4r (panel B) induced GSH depletion in HeLa cells. Cells were treated with the indicated concentration of $\mathbf{4 p}$ or $\mathbf{4 r}$ and $100 \mu \mathrm{M}$ NAC, as indicated. After 24 $\mathrm{h}$ incubations, the cells were stained with the fluorescent probe CMFDA and analyzed by flow cytometry. Data represent means \pm S.E.M. of three independent experiments. ${ }^{*} p<0.01$ vs compound alone. 
<smiles>O=C(O)C=Cc1cccc([N+](=O)[O-])c1</smiles>

$5 a$<smiles>CCNC(=O)/C=C/c1cccc([N+](=O)[O-])c1</smiles>

6a-p or<smiles>O=C(O)C=Cc1ccc([N+](=O)[O-])cc1</smiles>

a

or<smiles>O=C(/C=C/c1ccc([N+](=O)[O-])cc1)N[Tl]</smiles>

b<smiles>Nc1cccc(/C=C/C(=O)N[Ga])c1</smiles>

or<smiles>[3H]NC(=O)/C=C/c1ccc(N)cc1</smiles>

c<smiles>C=C(Br)C(=O)Nc1cccc(/C=C/C(=O)NC(=O)[O-])c1</smiles>

6-7a, $4 a, A r=\mathrm{C}_{6} \mathrm{H}_{5}$ 6-7b, 4b, Ar=napht-1-yl 6-7c, 4c, $\mathrm{Ar}=4-\mathrm{F}-\mathrm{C}_{6} \mathrm{H}_{5}$ 6-7d, 4d, Ar=3-F- $\mathrm{C}_{6} \mathrm{H}_{5}$ 6-7e, 4e, $\mathrm{Ar}=3,4-\mathrm{F}_{2}-\mathrm{C}_{6} \mathrm{H}_{4}$ 6-7f, 4f, $\mathrm{Ar}=4-\mathrm{Cl}-\mathrm{C}_{6} \mathrm{H}_{5}$ 6-7g, 4g, $\mathrm{Ar}=4-\mathrm{CH}_{3}-\mathrm{C}_{6} \mathrm{H}_{5}$ 6-7h, 4h, $\mathrm{Ar}=4-\mathrm{CH}_{3}-\mathrm{C}_{6} \mathrm{H}_{4} \mathrm{CH}_{2}$ 6-7i, $4 \mathbf{i}, \mathrm{Ar}=4-\mathrm{OCH}_{3}-\mathrm{C}_{6} \mathrm{H}_{5}$ 6-7j, 4j, $\mathrm{Ar}=4-\mathrm{OC}_{2} \mathrm{H}_{5}-\mathrm{C}_{6} \mathrm{H}_{5}$ 6-7k, 4k, $\mathrm{Ar}=4-\mathrm{OCF}_{3}-\mathrm{C}_{6} \mathrm{H}_{5}$ 6-7I, 4I, $\mathrm{Ar}=4-\mathrm{SCF}_{3}-\mathrm{C}_{6} \mathrm{H}_{5}$ 6-7m, $4 \mathrm{~m}, \mathrm{Ar}=3,4-\left(\mathrm{OCH}_{3}\right)_{2}-\mathrm{C}_{6} \mathrm{H}_{4}$ 6-7n, 4n, $\mathrm{Ar}=3,5-\left(\mathrm{OCH}_{3}\right)_{2}-\mathrm{C}_{6} \mathrm{H}_{4}$ 6-7o, 4o, $\mathrm{Ar}=3,4,5-\left(\mathrm{OCH}_{3}\right)_{3}-\mathrm{C}_{6} \mathrm{H}_{3}$ 6-7p, 4p, Ar=4-(morpholin-4'-yl)- $\mathrm{C}_{6} \mathrm{H}_{5}$<smiles>C=C(Br)C(=O)Nc1ccc(/C=C/C(=O)NC(=O)[O-])cc1</smiles>

6-7q, 4q, $\mathrm{Ar}=4-\mathrm{OCH}_{3}-\mathrm{C}_{6} \mathrm{H}_{5}$ 6-7r, 4r, $\mathrm{Ar}=3,4,5-\left(\mathrm{OCH}_{3}\right)_{3}-\mathrm{C}_{6} \mathrm{H}_{3}$

Scheme 1.

Reagents: a. $\mathrm{ArNH}_{2}, \mathrm{POCl}_{3}$, TEA, $\mathrm{CH}_{2} \mathrm{Cl}_{2} ; \mathbf{b}$ : $\mathrm{SnCl}_{2} \mathrm{H}_{2} \mathrm{O}$, EtOH, reflux; c: a-bromoacrylic acid, EDCI, DMF, rt, $18 \mathrm{~h}$. 
<smiles>[R6]Oc1cccc(/C=C/C(=O)Nc2cc(OC)c(OC)c(OC)c2)c1</smiles>

1a, $\mathrm{R}=\mathrm{CH}_{3}$ 1b, $\mathrm{R}=\mathrm{CH}_{2} \mathrm{C}_{6} \mathrm{H}_{5}$<smiles>[R]c1ccc(NC(=O)/C=C/c2ccccc2)c(C(N)=O)c1</smiles>

$\mathrm{R}=\mathrm{Cl}, \mathrm{Br}$, I or $\mathrm{CH}_{3}$.<smiles>C=C(Br)C(=O)Nc1cc(C(=O)NCCNC(=N)N)n(C)c1</smiles>

PNU-166196 or Brostallicin (3)<smiles>[3H]NC(=O)/C=C/c1cccc(NC(=O)C(=C)Br)c1</smiles>

4a, $\mathrm{Ar}=\mathrm{C}_{6} \mathrm{H}_{5}$ 4b, Ar=napht-1-yl 4c, $\mathrm{Ar}=4-\mathrm{F}-\mathrm{C}_{6} \mathrm{H}_{5}$ 4d, $\mathrm{Ar}=3-\mathrm{F}-\mathrm{C}_{6} \mathrm{H}_{5}$ 4e, $\mathrm{Ar}=3,4-\mathrm{F}_{2}-\mathrm{C}_{6} \mathrm{H}_{4}$ 4f, $\mathrm{Ar}=4-\mathrm{Cl}-\mathrm{C}_{6} \mathrm{H}_{5}$ 4g, $\mathrm{Ar}=4-\mathrm{CH}_{3}-\mathrm{C}_{6} \mathrm{H}_{5}$ 4h, $\mathrm{Ar}=4-\mathrm{CH}_{3}-\mathrm{C}_{6} \mathrm{H}_{4} \mathrm{CH}_{2}$ 4i, $\mathrm{Ar}=4-\mathrm{OCH}_{3}-\mathrm{C}_{6} \mathrm{H}_{5}$ $4 \mathrm{j}, \mathrm{Ar}=4-\mathrm{OC}_{2} \mathrm{H}_{5}-\mathrm{C}_{6} \mathrm{H}_{5}$ 4k, $\mathrm{Ar}=4-\mathrm{OCF}_{3}-\mathrm{C}_{6} \mathrm{H}_{5}$ 4I, $\mathrm{Ar}=4-\mathrm{SCF}_{3}-\mathrm{C}_{6} \mathrm{H}_{5}$ $4 \mathrm{~m}, \mathrm{Ar}=3,4-\left(\mathrm{OCH}_{3}\right)_{2}-\mathrm{C}_{6} \mathrm{H}_{4}$ $4 n, \mathrm{Ar}=3,5-\left(\mathrm{OCH}_{3}\right)_{2}-\mathrm{C}_{6} \mathrm{H}_{4}$ 4o, $\mathrm{Ar}=3,4,5-\left(\mathrm{OCH}_{3}\right)_{3}-\mathrm{C}_{6} \mathrm{H}_{3}$ $4 p, A r=4-\left(\right.$ morpholin-4'-yl) $-\mathrm{C}_{6} \mathrm{H}_{5}$<smiles>C=C(Br)C(=O)Nc1ccc(/C=C/C(=O)N[Ga])cc1</smiles>

4q, $\mathrm{Ar}=4-\mathrm{OCH}_{3}-\mathrm{C}_{6} \mathrm{H}_{5}$ $4 r, \mathrm{Ar}=3,4,5-\left(\mathrm{OCH}_{3}\right)_{3}-\mathrm{C}_{6} \mathrm{H}_{3}$

Chart 1.

Structure of phenylcinnamides $\mathbf{1 a}, \mathbf{1 b}$ and $\mathbf{2}$, brostallicin (3) and a-bromoacryloylamido arylcinnamides $\mathbf{4 a}-\mathbf{r}$. 


\section{Table 2}

Cytotoxicity of $\mathbf{4 p}$ and $\mathbf{4 r}$ for human peripheral blood mononuclear cells (PBMC).

\begin{tabular}{lcc}
\hline Cell line & $\mathbf{I C}_{\mathbf{5 0}}(\boldsymbol{\mu M})^{\boldsymbol{a}}$ & \\
\cline { 2 - 3 } & $\mathbf{4 p}$ & $\mathbf{4 r}$ \\
\hline $\mathrm{PBMC}_{\mathrm{resting}} b$ & $4.0 \pm 1.9$ & $3.5 \pm 1.8$ \\
$\mathrm{PBMC}_{\mathrm{PHA}} c$ & $0.50 \pm 0.27$ & $0.24 \pm 0.12$ \\
\hline
\end{tabular}

Values are the mean \pm SEM for three separate experiments.

${ }^{a}$ Compound concentration required to reduce cell growth inhibition by $50 \%$.

$b_{\text {PBMC not stimulated with PHA. }}$

${ }^{c}$ PBMC stimulated with PHA. 
Table 3

In vitro cell growth inhibitory effects of compounds $\mathbf{4 p}$ and $\mathbf{4 r}$ on drug-resistant cell lines.

\begin{tabular}{llll}
\hline Compd & $\mathbf{I C}_{\mathbf{5 0}} \boldsymbol{a}_{(\boldsymbol{\mu M})}$ & & \\
\cline { 2 - 4 } & $\mathbf{L o V o}$ & $\mathbf{L o V o}^{\text {Doxo }}$ & Resistance ratio $^{\boldsymbol{b}}$ \\
\hline $\mathbf{4 p}$ & $0.51 \pm 0.11$ & $1.05 \pm 0.44$ & 2.0 \\
$\mathbf{4 r}$ & $2.1 \pm 0.9$ & $1.37 \pm 0.24$ & 0.6 \\
Doxorubicin & $0.09 \pm 0.043$ & $11.3 \pm 0.35$ & 118 \\
\hline & $\mathrm{CEM}$ & $\mathrm{CEM}^{\mathrm{Vbl}-100}$ & Resistance ratio $^{b}$ \\
\hline $\mathbf{4 p}$ & $0.61 \pm 0.08$ & $0.41 \pm 0.09$ & 0.7 \\
$\mathbf{4 r}$ & $0.025 \pm 0.013$ & $0.015 \pm 0.005$ & 0.6 \\
$\mathbf{V i n b l a s t i n e}$ & $0.002 \pm 0.0005$ & $0.021 \pm 0.008$ & 105 \\
\hline
\end{tabular}

${ }^{a}{ }_{\mathrm{IC} 50}=$ compound concentration required to inhibit tumor cell proliferation by $50 \%$. Data are presented as the means \pm SE from the doseresponse curves of at least three independent experiments.

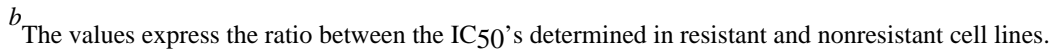

